\title{
Panorama Teórico e Empírico dos Determinantes da Transparência Pública
}

\section{Theoretical and Empirical Overview of the Determinants of Public Transparency}

\author{
Juliano Francisco Baldissera \\ Mestre em Contabilidade pelo Programa de Pós-Graduação em Contabilidade - PPGC, do \\ Centro de Ciências Sociais Aplicadas da Universidade Estadual do Oeste do Paraná - \\ UNIOESTE, professor do curso de Ciências Contábeis da Universidade Estadual de Maringá \\ (UEM), \\ juliano.baldissera@hotmail.com
}

\begin{abstract}
Denis Dall Asta
Doutor em Engenharia de Produção pelo Programa de Pós-Graduação em Engenharia de Produção (PPGEP) da Universidade Federal de Santa Catarina (UFSC), professor do curso de Ciências Contábeis da Universidade Estadual do Oeste do Paraná (Unioeste) denis.asta@unioeste.br
\end{abstract}

\section{Resumo}

O objetivo dessa pesquisa é analisar os determinantes da transparência pública observados na literatura teórica e empírica. Para tanto, desenvolveu-se uma pesquisa descritiva, documental e essencialmente qualitativa. Realizou-se uma busca e análise de artigos indexados nas bases científicas SPELL, SCOPUS e Web of Science, resultando ao final 33 artigos, os quais, com o auxílio da análise bibliométrica e de conteúdo, permitiram compreender o panorama das pesquisas relacionadas aos determinantes da transparência pública. Entre as características socioeconômicas, a população, renda municipal e educação tem demonstrado exercer influência positiva na transparência pública, justificado pelo fato de que esses fatores caracterizam a situação do município, estão relacionados à capacidade dos cidadãos em realizar pressões e exigir informações dos órgãos públicos. Já características financeiras-orçamentárias, como as contas públicas do governo, sua condição financeira, seu nível de dívida, arrecadação de receitas e dependência de recursos de outros entes, também exercem influência na transparência. Essa associação é devida a necessidade de governos em realizar práticas e estruturas cujo objetivo é demonstrar que estão cumprindo seu dever de transparência e responsabilidade quanto ao uso dos recursos financeiros e orçamentários públicos. O ambiente político e eleitoral, utilizando-se das variáveis competição política, ideologia política e coligação partidária têm se consagrado nos estudos, capta possíveis interesses particulares dos gestores sobre a transparência, dado a existência de ciclos políticos e o comportamento oportunista para se manter no poder ou ser reeleito. Por fim, tem-se os aspectos governamentais, abrangendo variáveis como o preço dos impostos, a qualidade de auditoria, o tipo de governo e a burocracia, em que a associação é devido ao fato de retratarem a forma como as entidades públicas formulam, planejam, implementam suas políticas públicas e controlam suas funções estatais visando o bem-estar social

Palavras-chave: Administração Pública; Transparência Pública; Gestão Pública; Governo; Informação.

\footnotetext{
Abstract

The purpose of this research is to analyze the determinants of public transparency observed in the theoretical and empirical literature. To do so, develop a descriptive, documentary and qualitative research. Conducted a search and analysis of articles indexed in the scientific bases Submetido em 24/09/2019 e aceito em 08/06/2020 por Diana Lima após o processo de Double Blind Review
} 
SPELL, SCOPUS and Web of Science, resulting in the end of 33 articles, which, with the aid of bibliographic and content analysis, allowed the presentation or overview of the analyzes related to the determinants of transparency public. Among the socioeconomic characteristics, the population, the municipal income and education that demonstrate a positive influence on the public economy, justified by the fact that these factors characterize a situation in the municipality, related to the capacity of citizens to put pressure and use information from citizens. public agencies. It already has financial-budgetary resources, such as government public accounts, its financial condition, its debt level, revenue collection and dependence on resources from other resources, also influence transparency. This association is necessary for the need to implement practices and structures whose objective is to demonstrate that they are fulfilling their duty of transparency and responsibility regarding the use of public financial and budgetary resources. The political and electoral environment, using changes in political politics, ideology and party politics, including studies, captures possible private interests of managers about transparency, exposure data of political cycles and the opportune behavior to maintain or not be reelected. Finally, there are the managed aspects, covering variables such as tax prices, audit quality, type of government and bureaucracy, in which association is due to the fact of portraying a format as formulated, planned public entities, implementing their policies public and control their state functions touching or social welfare

Keywords: Public administration; Public transparency; Public Management; Government; Information.

\section{INTRODUÇÃO}

A transparência é considerada como um valor democrático por excelência que sustenta um governo confiável de alto desempenho e responsável (GRIMMELIKHUIJSEN; WELCH, 2012; HOOD, 2006). A compreensão do conceito, determinantes e consequências podem ser úteis nos estudos sobre a transparência (GRIMMELIKHUIJSEN; WELCH, 2012).

Existem muitas definições sobre a transparência, mas todas afirmam o aspecto fundamental da acessibilidade da informação como o ponto principal (SOL, 2013). Também pode ser visualizada como o aumento do fluxo de informação econômica, social e política de forma tempestiva e confiável, acessível a todas as partes interessadas relevantes (KRAAY; KAUFMANN, 2002), ou então como a informação tempestiva sobre dados econômicos (ISLAM, 2006).

A transparência é desejável na perspectiva econômica porque aumenta a eficiência na alocação de recursos, reduzindo os problemas entre o principal e agente (HÖLMSTROM, 1979), desencorajando atividades de rent-seeking ou busca de rendas (CALDERÓN; CHONG, 2006). Entretanto, o homem é um maximizador de utilidade (BUCHANAN; TULLOCK, 1962), egoísta e racional (MUELLER, 1976), o que seria evidente nos políticos a frente do comando da gestão pública (BUCHANAN; TULLOCK, 1962; MUELLER, 1976).

Estudos demonstram a importância de fatores para explicar o nível de transparência nos diferentes níveis de governo e entre os governos. Entre esses estudos, eles parecem associar a diferentes tipos de determinantes, mas em comum, observa-se o destaque de aspectos socioeconômicos, financeiros, orçamentários, políticos, eleitorais e governamentais (RODRÍGUEZ BOLÍVAR; ALCAIDE MUÑOZ; LÓPEZ HERNÁNDEZ, 2013).

Dado a relevância do tema e a quantidade de pesquisas nesse sentido, é importante olhar para a literatura e entender os principais resultados, determinantes, conclusões nesse assunto, de modo que seja possível visualizar um panorama geral atual e lacunas ainda a serem preenchidas. Deste modo, essa pesquisa guia-se pela seguinte questão: quais os determinantes da transparência pública observados na literatura teórica e empírica? Para responder a essa questão, tem-se como objetivo analisar os determinantes da transparência pública observados na literatura teórica e empírica. 
Essa pesquisa contribui com a própria teoria e estudos no tema, pois busca observar os pressupostos que essa estabelece, principalmente por estar observando as organizações públicas. Como contribuição prática, tem-se o próprio fortalecimento do controle social, pois apresenta diversas práticas e explicações sobre a gestão pública. Busca-se, portanto, estabelecer um panorama teórico e empírico dos determinantes da transparência pública para que as próximas pesquisas sobre o tema possam avançar e contribuir além do que já realizado na literatura.

Desenvolveu-se uma pesquisa descritiva, documental e essencialmente qualitativa. Realizou-se uma busca e análise de artigos indexados nas principais bases científicas, os quais, com o auxílio da análise bibliométrica e de conteúdo, permitiram compreender o panorama das pesquisas relacionadas aos determinantes da transparência pública.

Este artigo foi estruturado de modo que, na próxima seção apresenta-se uma breve exposição sobre os aspectos teóricos relacionado aos determinantes da transparência pública, conceitos, definições e implicações da própria transparência, sua importância e discussões acadêmicas sobre o tema. A metodologia é exposta na terceira seção, sendo evidenciado a tipologia de estudo, instrumentos de coleta e análise dos dados. Na quarta seção são apresentados e discutidos os dados obtidos com a pesquisa. As considerações finais são apresentadas na quinta seção e buscam responder a pergunta de pesquisa, além de apresentar as limitações e sugestões para futuras pesquisas.

\section{REVISÃO DA LITERATURA}

Analisar a influência de diferentes fatores que impactam a transparência pública surge da necessidade de olhar sobre este contexto a partir da discussão teórica do conflito entre o principal e agente (LANE, 2006; SLOMSKI, 2005). A literatura teórica fornece importantes discussões e argumentos que permitem entender as implicações da transparência pública frente aos problemas entre o principal e agente, da assimetria de informação e dos ciclos políticos.

\subsection{Aspectos Teóricos}

A comunicação entre os gestores públicos e cidadãos, a partir de uma gestão transparente, de forma semelhante, estabelece uma relação de contrato social tácito entre o principal (cidadão) e o agente (gestor público), a qual pode ser explicada por essa perspectiva (BAIRRAL; SILVA; ALVES, 2015). Se esses indivíduos são maximizadores de utilidade, há razões para acreditar que o agente não irá agir conforme o interesse do principal (JENSEN; MECKLING, 1976).

Desta relação, surgem conflitos originados da assimetria da informação entre o principal e o agente devido à existência de três premissas: (1) o agente dispõe de diversos comportamentos possíveis de serem adotados; (2) a ação do agente afeta o bem-estar de ambas as partes; (3) as ações do agente dificilmente são observáveis pelo principal, que leva à existência da assimetria informacional (SLOMSKI, 2005).

Tem-se como premissa das relações de agência a existência de assimetria de informação dentro das organizações, o que cria condições para a ocorrência de problemas sistemáticos de credibilidade das informações trocadas entre principal e agente (OLIVEIRA; FONTES FILHO, 2017).

Existem duas fontes principais de problemas relacionados à assimetria de informação: (1) moral hazard (risco moral), relacionado com o acobertar ações, o qual reflete a falta de esforço por parte do agente que tem origem na incapacidade de o principal controlar todas as Panorama Teórico e Empírico dos Determinantes da Transparência Pública 
ações do agente; (2) adverse selection (seleção adversa), relacionado com acobertar informações (PRATT; ZECKHAUSER, 1985). O risco moral envolve situações onde as ações dos agentes não são de conhecimento do principal, ou são muito onerosas para serem observadas. A seleção adversa está relacionada ao fato de os agentes possuírem informações desconhecidas dos principais ou cujos custos de obtenção sejam elevados (SATO, 2007).

Dada a racionalidade limitada dos indivíduos, caracterizada pela posse limitada de informações, pelas limitações cognitivas e de tempo, da complexidade e do risco e incerteza, o oportunismo gerencial é multiplicado pela manipulação de assimetrias de informação para apropriação de fluxo de lucros (ou benefícios) e os problemas de seleção adversa e risco moral (FIANI, 2013; OLIVEIRA; FONTES FILHO, 2017). A quantidade e o tipo de informação revelada pelo agente, a princípio, garantem a sua permanência como agente, assegurando também a defesa dos seus interesses (CRUZ; FERREIRA; SILVA; MACEDO, 2012).

Estas assimetrias podem ser inerentes, também, aos ciclos políticos e eleitorais. A racionalidade limitada e o interesse dos eleitores pelo monitoramento das ações do governo permitem que os gestores públicos utilizem esse tipo de recurso para se favorecer no processo eleitoral e buscar se manter no poder (ROGOFF; SIBERT, 1988).

Esses ciclos derivariam de assimetrias informacionais, dada a existência de informação incompleta que proporciona ao político o incentivo de distorcer a política fiscal antes da eleição para aumentar sua probabilidade de reeleição (ROGOFF, 1990; ROGOFF; SIBERT, 1988; VICENTE; DO NASCIMENTO, 2012).

Os governantes começaram a ser chamados de "oportunistas" e "ideológicos". Oportunistas porque as escolhas políticas são feitas para maximizar a chance de sua reeleição sem se prender a situações passadas, à fidelidade aos ideais partidários ou aos impactos esperados na economia. Ideológicos pelo fato de que buscam focar em determinados objetivos sociais e políticos, não são movidos pela vontade de manutenção no poder e não buscam a popularidade junto aos eleitores (VICENTE; DO NASCIMENTO, 2012).

Os ciclos políticos orçamentários podem ser ampliados pelo impacto da transparência. A transparência pública implica ciclos orçamentários menores e, com isso, aumenta a estabilidade da política econômica e fiscal. Os decisores políticos consideram o impacto da transparência em relação às futuras promessas eleitorais, visto que os eleitores podem verificar o compromisso para com essas promessas (HERZOG, 2017).

Entre os efeitos da transparência em um contexto de informação imperfeita, ela pode influenciar as políticas fiscais. Os políticos são míopes, preferem gerar déficits maiores do que os cidadãos gostariam. Sob um contexto de alta transparência, as regras fiscais podem induzir os políticos a fazer os ajustes fiscais reais necessários para equilibrar o orçamento, enquanto que, sob baixa transparência, essas regras simplesmente incentivam a "contabilidade criativa" (ALT; LASSEN, 2006; MILESI-FERRETTI, 2004)

O aumento da transparência pode permitir que os eleitores melhorem os bons políticos contra os maus. Entretanto, por outro lado, uma maior transparência pode disciplinar os políticos na sua busca, o que pode torna mais difícil para os eleitores distinguirem entre políticos bons e maus. O resultado líquido na qualidade e no volume de negócios dos operadores históricos é ambíguo (BESLEY; SMART, 2007). Assim, observa-se que as discussões sobre transparência merecem cuidado.

\subsection{Transparência Pública}

A transparência se torna fundamental em um ambiente democrático, as ações do governo devem ser transparentes e de conhecimento do povo, de modo que permita responsabilizá-los, cobrá-los e puni-los pelos atos que não melhorem as condições da sociedade (CROSS, 1953). O debate se mostra necessário, dada a necessidade de compreensão das 
vantagens e desvantagens da transparência do governo para entender a dinâmica e a complexidade deste fenômeno (GRIMMELIKHUIJSEN; WELCH, 2012; MEIJER, 2009).

A transparência é dada como a divulgação de informações por parte de uma organização que permite aos atores externos monitorar e avaliar o seu funcionamento interno e desempenho. Essa definição, portanto, abrange dois tipos de divulgação: (1) transparência ativa, a qual é desenvolvida proativamente pela agência; (2) transparência passiva, a entidade responde de forma reativa às demandas externas por meio de pedidos de informação (GRIMMELIKHUIJSEN; WELCH, 2012).

Destas definições, se percebe que a transparência envolve três elementos: um observador, algo disponível para ser observado e um meio ou método de observação (OLIVER, 2004). Esse tipo de definição se baseia nas relações de agência entre principal e agente, visto que o principal requer informações sobre o agente para verificar se o agente está cumprindo com o "contrato" (PRAT, 2006).

A transparência consiste em uma relação institucional na qual ocorre uma troca de informações relacionada ao funcionamento ou ao desempenho de um agente. A transparência como uma relação institucional entre as organizações governamentais e a sociedade pode ser visualizada sobre um comportamento apropriado e quais os atores externos que devem ter acesso a informações governamentais. A transparência como uma troca de informação pode ser definida em termos de velocidade, acessibilidade, facilidade de uso etc. A transparência de funcionamento e desempenho pode mudar em termos dos domínios de atividade do governo que são transparentes (MEIJER, 2013).

Deste modo, o ambiente da transparência é construído e continuamente reconstruído por meio de processos sociais e políticos que envolvem as relações institucionais, intercâmbios de informações e domínios de transparência. Essas construções socioeconômicas resultam em estruturas legislativas, políticas de transparência e práticas (MEIJER, 2013). Assim, se observa que a transparência assume papel fundamental na consolidação democrática e na sustentabilidade macroeconômica (ZUCCOLOTTO; RICCIO; SAKATA, 2014).

\section{PROCEDIMENTOS METODOLÓGICOS}

Dado o objetivo de analisar os determinantes da transparência pública sob um aspecto teórico e empírico, desenvolveu-se uma pesquisa descritiva, uma vez que buscou-se analisar, comparar e descrever os resultados e conclusões obtidos na literatura teórica e empírica anterior. Trata-se de uma tipologia utilizada para descrever um fenômeno social, evidenciando sua forma e estrutura, além da sua própria evolução ao longo do tempo (GALL; BORG; GALL, 1996).

Desenvolveu-se esse estudo a partir de dados documentais, já que os artigos foram obtidos nas bases científicas SPELL, SCOPUS e Web of Science. Por fim, a abordagem do problema de pesquisa foi qualitativa e quantitativa, uma vez que realizou-se tanto a análise do conteúdo, como a análise estatística descritiva dessas pesquisas (RAUPP; BEUREN, 2006).

A coleta desses artigos ocorreu em dezembro de 2017 e partiu das três bases científicas mencionadas utilizando-se as seguintes palavras-chave: "governamental transparency", "government transparency", "fiscal transparency", "public transparency", "political transparency" e "policy transparency". Esse filtro foi aplicado sem limitar um período determinado, uma vez que buscava-se a maior abrangência possível dos estudos sobre o tema, de modo que fosse possível visualizar o panorama científico como um todo.

Esse filtro auxiliou encontrar a maior parte da literatura sobre o tema, mas ainda assim não foi suficiente. A partir desses artigos iniciais, foi possível buscar outros estudos cuja abordagem e contexto se assemelham a essa e que não retornaram apenas utilizados os filtros 
determinados. Essa análise guiou-se pelas citações, permitindo obter a literatura restante para o desenvolvimento dessa pesquisa.

A partir da leitura dos resumos, introdução e conclusão destes artigos, foi identificado os artigos com pertinência sobre tema dos determinantes da transparência pública. Esta seleção permitiu obter a amostra de pesquisa, a qual ficou limitada a 33 artigos.

A análise dos dados abrangeu dois métodos: análise bibliométrica e a análise de conteúdo. A análise bibliométrica permite o uso das técnicas estatísticas para a análise de bibliografia, o que caracteriza um aspecto quantitativo da análise da produção científica (FONSECA, 1986). Já a análise de conteúdo tem como objetivo compreender criticamente o sentido das comunicações, seu conteúdo manifesto ou latente, as significações, sejam elas explícitas ou implícitas (CHIZZOTTI, 2018).

A análise realizada foi feita a partir da tabulação dos dados em planilha eletrônica por meio do software Microsoft Excel®, coletando as informações referentes ao título, tema, objetivo, metodologia, principais resultados, ano da publicação, país e nível de governo em que foi aplicado o estudo, tipo de transparência analisada, variáveis significativas e relação encontrada (positiva ou negativa).

A partir dessa metodologia foi possível identificar as principais características em cada um dos estudos e entender o panorama geral das pesquisas sobre esse tema. A próxima seção apresenta a análise e discussão dos resultados encontrados.

\section{APRESENTAÇÃO E ANÁLISE DOS RESULTADOS}

Apesar de se observar muitos estudos quanto aos determinantes da transparência pública, ainda existe uma heterogeneidade considerável nos resultados, de modo que não permitiu obter evidências conclusivas sobre o tema, uma vez que ainda existe uma grande inconsistência nesses estudos (ALCAIDE MUÑOZ; RODRÍGUEZ BOLÍVAR; LÓPEZ HERNÁNDEZ, 2016; POMEROY; THORNTON, 2008).

Em relação aos fatores determinantes da transparência pública, existem diferentes incentivos para a divulgação de informações, como fatores internos e externos, socioeconômicos, políticos e gerenciais (ALCAIDE MUÑOZ; RODRÍGUEZ BOLÍVAR; LÓPEZ HERNÁNDEZ, 2016). Entre os diferentes grupos de variáveis determinantes, tem se consagrado as variáveis relacionadas a aspectos socioeconômicos, financeira-orçamentárias, políticas e governamentais.

Dessa forma, a partir dos 33 estudos analisados, os quais trabalharam com diferentes tipos de dados documentais, sintetizou-se os resultados e características de cada um desses estudos na Tabela 1. 
Sociedade, Contabilidade e Gestão, Rio de Janeiro, v. 15, n. 4, set/dez, 2020 DOI: https://doi.org/10.21446/scg ufrj.v0i0.28949

Tabela 1 - Principais Características dos Estudos Anteriores

\begin{tabular}{|c|c|c|c|c|c|c|c|}
\hline Autor/Estudos & País & $\begin{array}{c}\text { Tipo de } \\
\text { Transparência }\end{array}$ & $\begin{array}{l}\text { Nível de } \\
\text { Governo }\end{array}$ & $\begin{array}{c}\text { Variáveis } \\
\text { Socioeconômicas }\end{array}$ & $\begin{array}{c}\text { Variáveis } \\
\text { Financeiras- } \\
\text { Orçamentárias } \\
\end{array}$ & $\begin{array}{l}\text { Variáveis } \\
\text { Políticas }\end{array}$ & $\begin{array}{c}\text { Variáveis } \\
\text { Governamentais }\end{array}$ \\
\hline Ingram (1984) & EUA & $\begin{array}{l}\text { Relatórios } \\
\text { Anuais }\end{array}$ & Estadual & $\begin{array}{c}\text { Urbanização (+) } \\
\text { Mídia (-) }\end{array}$ & 3 & $\begin{array}{c}\text { Competição Política (+) } \\
\text { Seleção do } \\
\text { administrador }(+)\end{array}$ & - \\
\hline Giroux (1989) & EUA & $\begin{array}{l}\text { Demonstrações } \\
\text { Financeiras }\end{array}$ & Municipal & - & - & - & $\begin{array}{c}\text { Preço dos Impostos } \\
(-) \\
\text { Tipo de Governo (+) } \\
\text { Qualidade da } \\
\text { Auditoria (-) }\end{array}$ \\
\hline Cheng (1992) & EUA & $\begin{array}{l}\text { Demonstrações } \\
\text { Financeiras }\end{array}$ & Estadual & Mídia (-) & $\begin{array}{c}\text { Dívida (-) } \\
\text { Dependência Federal (-) }\end{array}$ & $\begin{array}{l}\text { Competição Política (-) } \\
\text { Grupos de Interesse (+) }\end{array}$ & $\begin{array}{l}\text { Governança (-) } \\
\text { Burocracia (+) }\end{array}$ \\
\hline Smith (2004) & EUA & $\begin{array}{l}\text { Demonstrações } \\
\text { Financeiras }\end{array}$ & Municipal & - & Dívida (-) & ( & 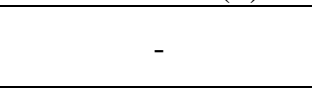 \\
\hline $\begin{array}{l}\text { Laswad et al. } \\
\text { (2005) }\end{array}$ & $\begin{array}{c}\text { Nova } \\
\text { Zelandia }\end{array}$ & $\begin{array}{l}\text { Transparência } \\
\text { Eletrônica }\end{array}$ & Municipal & Mídia (+) & - & - & - \\
\hline $\begin{array}{c}\text { Alt e Lassen } \\
\text { (2006) }\end{array}$ & OECD & $\begin{array}{l}\text { Transparência } \\
\text { Fiscal }\end{array}$ & Federal & - & Dívida (-) & - & - \\
\hline $\begin{array}{c}\text { Caba Pérez et } \\
\text { al. (2008) }\end{array}$ & Espanha & $\begin{array}{l}\text { Transparência } \\
\text { Eletrônica }\end{array}$ & Municipal & Acessibilidade (+) & Custo da Dívida (+) & - & - \\
\hline $\begin{array}{l}\text { Gandia e } \\
\text { Archidona } \\
(2008)\end{array}$ & Espanha & $\begin{array}{l}\text { Transparência } \\
\text { Eletrônica }\end{array}$ & Municipal & $\begin{array}{c}\text { Mídia (+) } \\
\text { Acesso à tecnologia (+) } \\
\text { Educação }(+)\end{array}$ & - & Competição Política (+) & - \\
\hline $\begin{array}{l}\text { Santana Junior } \\
\text { (2008) }\end{array}$ & Brasil & $\begin{array}{l}\text { Transparência } \\
\text { Fiscal }\end{array}$ & Estadual & $\begin{array}{c}\text { População (+) } \\
\text { Educação (+) } \\
\text { Riqueza Municipal (+) } \\
\text { Acesso à internet (+) }\end{array}$ & $\begin{array}{c}\text { Receita (+) } \\
\text { Despesa (+) } \\
\text { Receita Corrente Líquida } \\
(+) \\
\text { Ativo (+) } \\
\text { Passivo (+) } \\
\text { Dívida (+) }\end{array}$ & - & - \\
\hline $\begin{array}{l}\text { Serrano-Cinca } \\
\text { et al. }(2009)\end{array}$ & Espanha & $\begin{array}{c}\text { Transparência } \\
\text { Fiscal } \\
\text { Voluntária }\end{array}$ & Municipal & $\begin{array}{c}\text { População (+) } \\
\text { Riqueza Municipal (+) }\end{array}$ & - & $\begin{array}{c}\text { Participação Política } \\
(+)\end{array}$ & - \\
\hline
\end{tabular}


Sociedade, Contabilidade e Gestão, Rio de Janeiro, v. 15, n. 4, set/dez, 2020

\begin{tabular}{|c|c|c|c|c|c|c|c|}
\hline Autor/Estudos & País & $\begin{array}{c}\text { Tipo de } \\
\text { Transparência }\end{array}$ & $\begin{array}{l}\text { Nível de } \\
\text { Governo }\end{array}$ & $\begin{array}{c}\text { Variáveis } \\
\text { Socioeconômicas }\end{array}$ & $\begin{array}{c}\text { Variáveis } \\
\text { Financeiras- } \\
\text { Orçamentárias } \\
\end{array}$ & $\begin{array}{l}\text { Variáveis } \\
\text { Políticas }\end{array}$ & $\begin{array}{c}\text { Variáveis } \\
\text { Governamentais }\end{array}$ \\
\hline $\begin{array}{c}\text { Cárcaba-García } \\
\text { e García-García } \\
(2010) \\
\end{array}$ & Espanha & $\begin{array}{c}\text { Transparência } \\
\text { Fiscal } \\
\text { Voluntária } \\
\end{array}$ & Municipal & $\begin{array}{c}\text { População (+) } \\
\text { Mídia (-) }\end{array}$ & $\begin{array}{c}\text { Investimento de Capital } \\
(+)\end{array}$ & Competição Política (+) & - \\
\hline Cruz (2010) & Brasil & $\begin{array}{l}\text { Transparência } \\
\text { Eletrônica }\end{array}$ & Municipal & $\begin{array}{c}\text { Dinamismo Municipal } \\
(+)\end{array}$ & Receita (+) & - & - \\
\hline $\begin{array}{l}\text { Pina et al. } \\
\quad(2010)\end{array}$ & $\begin{array}{l}\text { União } \\
\text { Europeia }\end{array}$ & $\begin{array}{l}\text { Transparência } \\
\text { Fiscal }\end{array}$ & Municipal & População (+) & - & - & $\begin{array}{c}\text { Qualidade da } \\
\text { Auditoria (+) } \\
\text { Estilo de } \\
\text { Administração } \\
\text { Pública (+) } \\
\end{array}$ \\
\hline $\begin{array}{c}\text { Gallego- } \\
\text { Álvarez, et al. } \\
(2010)\end{array}$ & Internacional & $\begin{array}{l}\text { Transparência } \\
\text { Eletrônica }\end{array}$ & Municipal & População (+) & Despesa (+) & - & - \\
\hline $\begin{array}{l}\text { Guillamón et al. } \\
\text { (2011) }\end{array}$ & Espanha & $\begin{array}{l}\text { Transparência } \\
\text { Fiscal }\end{array}$ & Municipal & População (+) & $\begin{array}{c}\text { Receita Fiscal }(+) \\
\text { Transferências } \\
\text { Intergovernamentais }(+) \\
\end{array}$ & $\begin{array}{c}\text { Ideologia Política - } \\
\text { direta (-) }\end{array}$ & - \\
\hline $\begin{array}{l}\text { Esteller-Moré e } \\
\text { Otero (2012) }\end{array}$ & Espanha & $\begin{array}{c}\text { Transparência } \\
\text { Fiscal }\end{array}$ & Municipal & População (-) & (n) & Competição Política (-) & Descentralização (+) \\
\hline $\begin{array}{c}\text { Martani e } \\
\text { Lestiani (2012) }\end{array}$ & Indonesia & $\begin{array}{c}\text { Transparência } \\
\text { Fiscal }\end{array}$ & Municipal & $\begin{array}{l}\text { Renda per capita (+) } \\
\text { População }(+)\end{array}$ & - & - & $\begin{array}{l}\text { Qualidade da } \\
\text { Auditoria (+) }\end{array}$ \\
\hline $\begin{array}{l}\text { Caamaño- } \\
\text { Alegre } \text { et al. } \\
\text { (2013) }\end{array}$ & Espanha & $\begin{array}{l}\text { Transparência } \\
\text { Fiscal }\end{array}$ & Municipal & Desemprego (-) & $\begin{array}{l}\text { Saldo Público (+) } \\
\text { Despesa (-) }\end{array}$ & $\begin{array}{c}\text { Coligação Partidária (-) } \\
\text { Ideologia Política - } \\
\text { esquerda }(+)\end{array}$ & 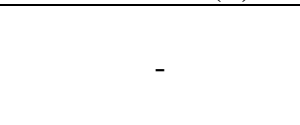 \\
\hline $\begin{array}{l}\text { García-Sánchez } \\
\text { et al. }(2013) \\
\end{array}$ & Espanha & $\begin{array}{c}\text { Transparência } \\
\text { Social } \\
\end{array}$ & Municipal & População (+) & - & $\begin{array}{c}\text { Ideologia Política - } \\
\text { Direita (-) } \\
\end{array}$ & - \\
\hline $\begin{array}{l}\text { Rios et al. } \\
\quad(2013)\end{array}$ & Internacional & $\begin{array}{l}\text { Transparência } \\
\text { Orçamentária }\end{array}$ & Federal & $\begin{array}{c}\text { Educação (+) } \\
\text { População (+) } \\
\text { Acesso à internet }(+)\end{array}$ & $\begin{array}{c}\text { Dívida (+) } \\
\text { Saldo Público (+) }\end{array}$ & $\begin{array}{c}\text { Competição Política (-) } \\
\text { Ideologia Política - } \\
\text { Direita (-) }\end{array}$ & $\begin{array}{c}\text { Estilo de } \\
\text { Administração } \\
\text { Pública (+) } \\
\end{array}$ \\
\hline $\begin{array}{c}\text { Rodríguez } \\
\text { Bolívar et al. } \\
(2013)\end{array}$ & $\begin{array}{l}\text { Meta- } \\
\text { Análise }\end{array}$ & $\begin{array}{l}\text { Transparência } \\
\text { Fiscal }\end{array}$ & - & $\begin{array}{c}\text { População (+) } \\
\text { Riqueza Municipal (+) }\end{array}$ & $\begin{array}{l}\text { Condição Financeira (+) } \\
\text { Transferências } \\
\text { Intergovernamentais }(+)\end{array}$ & Competição Política (+) & - \\
\hline Sol (2013) & Espanha & $\begin{array}{l}\text { Transparência } \\
\text { Eletrônica }\end{array}$ & Municipal & População (+) & o & $\begin{array}{l}\text { Ideologia Política - } \\
\text { Esquerda (+) } \\
\text { Maioria Política (-) }\end{array}$ & - \\
\hline
\end{tabular}


Sociedade, Contabilidade e Gestão, Rio de Janeiro, v. 15, n. 4, set/dez, 2020

\begin{tabular}{|c|c|c|c|c|c|c|c|}
\hline Autor/Estudos & País & $\begin{array}{c}\text { Tipo de } \\
\text { Transparência }\end{array}$ & $\begin{array}{l}\text { Nível de } \\
\text { Governo }\end{array}$ & $\begin{array}{c}\text { Variáveis } \\
\text { Socioeconômicas }\end{array}$ & $\begin{array}{c}\text { Variáveis } \\
\text { Financeiras- } \\
\text { Orçamentárias }\end{array}$ & $\begin{array}{l}\text { Variáveis } \\
\text { Políticas }\end{array}$ & $\begin{array}{c}\text { Variáveis } \\
\text { Governamentais }\end{array}$ \\
\hline $\begin{array}{c}\text { Wehner e } \\
\text { Renzio (2013) }\end{array}$ & Internacional & $\begin{array}{c}\text { Transparência } \\
\text { Fiscal }\end{array}$ & Federal & $\begin{array}{l}\text { Idade }(+) \\
\text { PIB }(+)\end{array}$ & 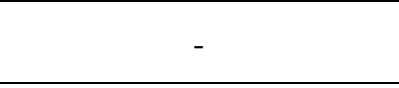 & Democracia (+) & - \\
\hline $\begin{array}{c}\text { Caba Pérez et } \\
\text { al. }(2014)\end{array}$ & $\begin{array}{c}\text { Países da } \\
\text { OECD }\end{array}$ & $\begin{array}{l}\text { Transparência } \\
\text { Fiscal }\end{array}$ & Federal & - & Dívida (-) & Competição Política (+) & Tipo de Governo (-) \\
\hline $\begin{array}{l}\text { Alcaraz-Quiles } \\
\text { et al. }(2015) \\
\end{array}$ & Espanha & $\begin{array}{c}\text { Transparência } \\
\text { Social } \\
\end{array}$ & Municipal & - & Autonomia Financeiro (+) & 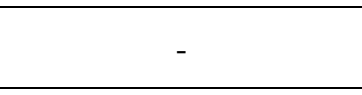 & $\begin{array}{c}\text { Preço dos Impostos } \\
(-)\end{array}$ \\
\hline $\begin{array}{l}\text { Bairral et } \\
\text { al.(2015) }\end{array}$ & $\begin{array}{l}\text { Brasil, } \\
\text { Órgãos } \\
\text { Federais }\end{array}$ & $\begin{array}{l}\text { Relatórios } \\
\text { Anuais }\end{array}$ & Estadual & Acessibilidade (+) & Gasto com Pessoal (+) & - & $\begin{array}{c}\text { Tipo de Governo (+) } \\
\text { Burocracia (-) }\end{array}$ \\
\hline $\begin{array}{l}\text { Garcia-Tabuyo } \\
\text { et al. }(2015) \\
\end{array}$ & $\begin{array}{l}\text { América } \\
\text { Central }\end{array}$ & $\begin{array}{c}\text { Transparência } \\
\text { Eletrônica }\end{array}$ & Municipal & Acesso à internet (+) & - & - & $\begin{array}{c}\text { LAI (-) } \\
\text { Corrupção (-) } \\
\end{array}$ \\
\hline $\begin{array}{l}\text { Keerasuntonpon } \\
\text { et al. }(2015) \\
\end{array}$ & $\begin{array}{c}\text { Nova } \\
\text { Zelandia }\end{array}$ & $\begin{array}{c}\text { Declarações de } \\
\text { Desempenho }\end{array}$ & Municipal & $\begin{array}{c}\text { População (+) } \\
\text { Renda per capita }(+)\end{array}$ & $\begin{array}{l}\text { Ativos (+) } \\
\text { Receita (+) }\end{array}$ & - & - \\
\hline $\begin{array}{l}\text { Lowatcharin e } \\
\text { Menifield } \\
\text { (2015) }\end{array}$ & EUA & $\begin{array}{l}\text { Transparência } \\
\text { Eletrônica }\end{array}$ & Municipal & $\begin{array}{c}\text { Acesso à internet }(+) \\
\text { População }(+) \\
\text { Educação }(+) \\
\text { Renda per capita }(+) \\
\text { Região }(+) \\
\end{array}$ & 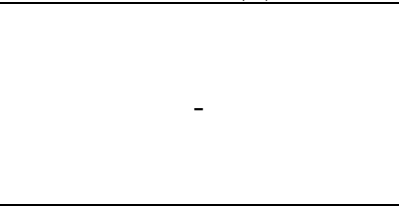 & - & - \\
\hline $\begin{array}{l}\text { Guillamón et al. } \\
\text { (2016) }\end{array}$ & $\begin{array}{l}\text { Itália e } \\
\text { Espanha }\end{array}$ & $\begin{array}{l}\text { Transparência } \\
\text { Eletrônica }\end{array}$ & Municipal & $\begin{array}{c}\text { População (+) } \\
\text { Renda per capita (-) }\end{array}$ & Alavancagem (-) & - & - \\
\hline $\begin{array}{l}\text { Alcaide Muñoz } \\
\text { et al. }(2016)\end{array}$ & $\begin{array}{l}\text { Meta- } \\
\text { Análise }\end{array}$ & $\begin{array}{l}\text { Transparência } \\
\text { Fiscal }\end{array}$ & - & $\begin{array}{c}\text { População (+) } \\
\text { Riqueza Municipal (+) }\end{array}$ & $\begin{array}{c}\text { Condição Financeira (+) } \\
\text { Transferências } \\
\text { Intergovernamentais }(+) \\
\end{array}$ & Competição Política (+) & - \\
\hline $\begin{array}{l}\text { Fiirst et al. } \\
\quad(2017)\end{array}$ & Brasil & $\begin{array}{l}\text { Transparência } \\
\text { Eletrônica }\end{array}$ & Municipal & População (+) & $\begin{array}{c}\text { Condição Financeira (-) } \\
\text { Receita (-) } \\
\text { Transferências } \\
\text { Intergovernamentais (-) } \\
\end{array}$ & - & 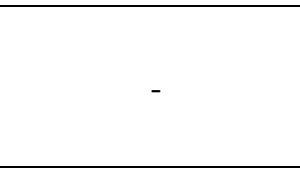 \\
\hline $\begin{array}{c}\text { Puron-Cid e } \\
\text { Bolívar (2017) }\end{array}$ & México & $\begin{array}{l}\text { Transparência } \\
\text { Fiscal }\end{array}$ & Municipal & $\begin{array}{c}\text { PIB (-) } \\
\text { Desenvolvimento (-) }\end{array}$ & 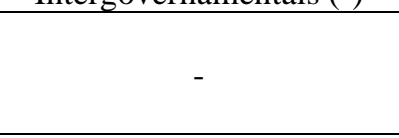 & - & $\begin{array}{c}\text { LAI (+) } \\
\text { Preço dos Impostos } \\
(+)\end{array}$ \\
\hline
\end{tabular}

Legenda: (+) quando a variável apresentou uma associação positiva e significativa; (-) quando a variável apresentou uma associação negativa e significativa. Fonte: os autores (2019). 
Com a Tabela 1 é possível observar a heterogeneidade nos resultados obtidos da literatura anterior. Além disso, também permite indicar os resultados empíricos que tem se destacado na literatura anterior. Também observa-se que não existem diferenças significativas nas variáveis exploradas por cada estudo em cada país, mas observa-se que eles tendem a explorar características inerentes aos aspectos inerentes a cada modelo de administração pública.

Diferentes características, técnicas, países e variáveis utilizadas justificam a diversidade dos resultados encontrados. Entretanto, observa-se que a literatura internacional mais recente tem se encaminhado para observar os fatores socioeconômicos, financeiros-orçamentários (denominados institucionais) e políticos.

Além disso, observa-se que muitas das variáveis socioeconômicas se consagraram na literatura, ao mesmo tempo em que em anos mais recentes outras variáveis têm ganhado destaque, principalmente no que se refere aos aspectos financeiro-orçamentários e governamentais, a citar as variáveis condição financeira, transferências intergovernamentais, preço dos impostos e tipo de governo.

A Tabela 2 evidencia os determinantes socioeconômicos e relação (positiva, negativa ou não significante) encontrada em cada um dos estudos analisados (ALCAIDE MUNOOZ; RODRÍGUEZ BOLÍVAR; LÓPEZ HERNÁNDEZ, 2016; ALCARAZ-QUILES; NAVARROGALERA; ORTIZ-RODRIGUEZ, 2015; ALT; LASSEN, 2006; CABA PÉREZ; PEDRO RODRÍGUEZ BOLÍVAR; LÓPEZ HERNÁNDEZ, 2008; CRUZ; SILVA; SANTOS, 2010; FIIRST; COSTA; BALDISSERA; DALL'ASTA， 2017; GALLEGO-ÁLVAREZ; RODRIIGUEZ-DOMÍNGUEZ; GARCÍA-SÁNCHEZ, 2010; GARCÍA-SÁNCHEZ; FRÍASACEITUNO; RODRÍGUEZ-DOMÍNGUEZ, 2013; GARCÍA-TABUYO; SÁEZ-MARTÍN; CABA-PÉREZ, 2016; GUILLAMÓN; BASTIDA; BENITO, 2011; GUILLAMÓN; RÍOS; GESUELE; METALLO, 2016; KEERASUNTONPONG; DUNSTAN; KHANNA, 2015; LASWAD; FISHER; OYELERE, 2005; LOWATCHARIN; MENIFIELD, 2015; PINA; TORRES; ROYO, 2010; PURON-CID; BOLÍVAR, 2018; SANTANA JUNIOR, 2008; SERRANO-CINCA; RUEDA-TOMÁS; PORTILLO-TARRAGONA, 2009; SOL, 2013).

Tabela 2 - Determinantes Socioeconômicos nos Estudos Anteriores

\begin{tabular}{|c|c|c|}
\hline Variáveis & Relação & Autores \\
\hline \multicolumn{3}{|r|}{ DETERMINANTES SOCIOECONÔMICOS } \\
\hline \multirow[t]{3}{*}{ População } & + & $\begin{array}{l}\text { Santana Junior (2008); Serrano-Cinca et al. (2009); Cárcaba-García e } \\
\text { García-García (2010); Pina et al. (2010); Gallego-Álvarez, et al. (2010); } \\
\text { Guillamón et al. (2011); Martani e Lestiani (2012); García-Sánchez et al. } \\
\text { (2013); Rios et al. (2013); Rodríguez Bolívar et al. (2013); Sol (2013); } \\
\text { Keerasuntonpon et al. (2015); Lowatcharin e Menifield (2015); } \\
\text { Guillamón et al. (2016); Alcaide Muñoz et al. (2016); Fiirst et al. (2017) }\end{array}$ \\
\hline & - & Esteller-Moré e Otero (2012); \\
\hline & NS & $\begin{array}{l}\text { Smith (2004); Caba Pérez et al. (2008); Gandia e Archidona (2008); } \\
\text { Caamaño-Alegre et al. (2013); Caba Pérez et al. (2014); Alcaraz-Quiles } \\
\text { et al. (2015); Garcia-Tabuyo et al. (2015); }\end{array}$ \\
\hline \multirow{2}{*}{ Desemprego } & - & Caamaño-Alegre et al. (2013); \\
\hline & NS & García-Sánchez et al. (2013); Sol (2013); Alcaraz-Quiles et al. (2015); \\
\hline Urbanização & + & Ingram (1984); \\
\hline \multirow{3}{*}{ Mídia } & + & Laswad et al. (2005); Gandia e Archidona (2008); \\
\hline & - & Ingram (1984); Cheng (1992); Cárcaba-García e García-García (2010); \\
\hline & NS & Serrano-Cinca et al. (2009); Laswad et al. (2005); \\
\hline \multirow{2}{*}{ Educação } & + & $\begin{array}{l}\text { Gandia e Archidona (2008); Santana Junior (2008); Rios et al. (2013); } \\
\text { Lowatcharin e Menifield (2015); }\end{array}$ \\
\hline & NS & $\begin{array}{l}\text { Caba Pérez et al. (2008); Serrano-Cinca et al. (2009); Cruz (2010); Caba } \\
\text { Pérez et al. (2014); Alcaraz-Quiles et al. (2015); Guillamón et al. (2016); }\end{array}$ \\
\hline \multirow{2}{*}{ Acessibilidade } & + & Caba Pérez et al. (2008); Bairral et al. (2015); \\
\hline & NS & Cruz (2010); Pina et al. (2010); Caba Pérez et al. (2014); \\
\hline
\end{tabular}




\begin{tabular}{|c|c|c|}
\hline \multirow[t]{2}{*}{ Acesso à internet } & + & $\begin{array}{l}\text { Gandia e Archidona (2008); Rios et al. (2013); Lowatcharin e Menifield } \\
\text { (2015); }\end{array}$ \\
\hline & NS & Pina et al. (2010); Alcaraz-Quiles et al. (2015); Guillamón et al. (2016); \\
\hline \multirow{3}{*}{ Região } & + & Lowatcharin e Menifield (2015); \\
\hline & - & Gallego-Álvarez, et al. (2010); \\
\hline & NS & Cruz (2010); \\
\hline \multirow{2}{*}{ Desenvolvimento } & - & Puron-Cid e Bolívar (2017) \\
\hline & NS & Cruz (2010); Fiirst et al. (2017) \\
\hline $\begin{array}{l}\text { Dinamismo } \\
\text { Municipal }\end{array}$ & + & Cruz (2010); \\
\hline Sustentabilidade & NS & García-Sánchez et al. (2013); \\
\hline \multirow{2}{*}{ Idade } & + & Wehner e Renzio (2013); \\
\hline & NS & Lowatcharin e Menifield (2015); \\
\hline Condição Econômica & NS & Smith (2004); \\
\hline $\begin{array}{c}\text { Atividade } \\
\text { Econômica }\end{array}$ & NS & Sol (2013); \\
\hline \multirow{3}{*}{ PIB } & + & Wehner e Renzio (2013); \\
\hline & - & Puron-Cid e Bolívar (2017) \\
\hline & NS & $\begin{array}{l}\text { Cruz (2010); Rios et al. (2013); Caba Pérez et al. (2014); Fiirst et al. } \\
\text { (2017) }\end{array}$ \\
\hline \multirow{3}{*}{ Renda per capita } & + & $\begin{array}{l}\text { Santana Junior (2008); Serrano-Cinca } \text { et al. (2009); Martani e Lestiani } \\
\text { (2012); Rodríguez Bolívar } \text { et al. (2013); Keerasuntonpon et al. (2015); } \\
\text { Lowatcharin e Menifield (2015); Alcaide Muñoz et al. (2016) }\end{array}$ \\
\hline & - & Guillamón et al. (2016); \\
\hline & NS & $\begin{array}{l}\text { Giroux (1989); Laswad et al. (2005); Pina et al. (2010); Guillamón et al. } \\
\text { (2011); Caba Pérez et al. (2014); Alcaraz-Quiles et al. (2015); Fiirst et al. } \\
\text { (2017) }\end{array}$ \\
\hline
\end{tabular}

Legenda: (+) quando a variável apresentou uma associação positiva e significativa; (-) quando a variável apresentou uma associação negativa e significativa. NS quando a variável não apresentou uma associação significativa

Fonte: os autores (2019).

Os fatores socioeconômicos representam os fatores sociais e econômicos que caracterizam a situação do município, estão relacionados à capacidade dos cidadãos em realizar pressões e exigir informações dos órgãos públicos. Os estudos têm utilizado diversas variáveis para representar as características socioeconômicas da entidade pública, entre estas tem se consagrado o uso das variáveis população, renda per capita, educação e acesso à internet, conforme é apresentado na Figura 1, a qual evidencia a quantidade de estudos que obtiveram algum tipo de relação para cada uma das variáveis relacionadas a aspectos socioeconômicos.

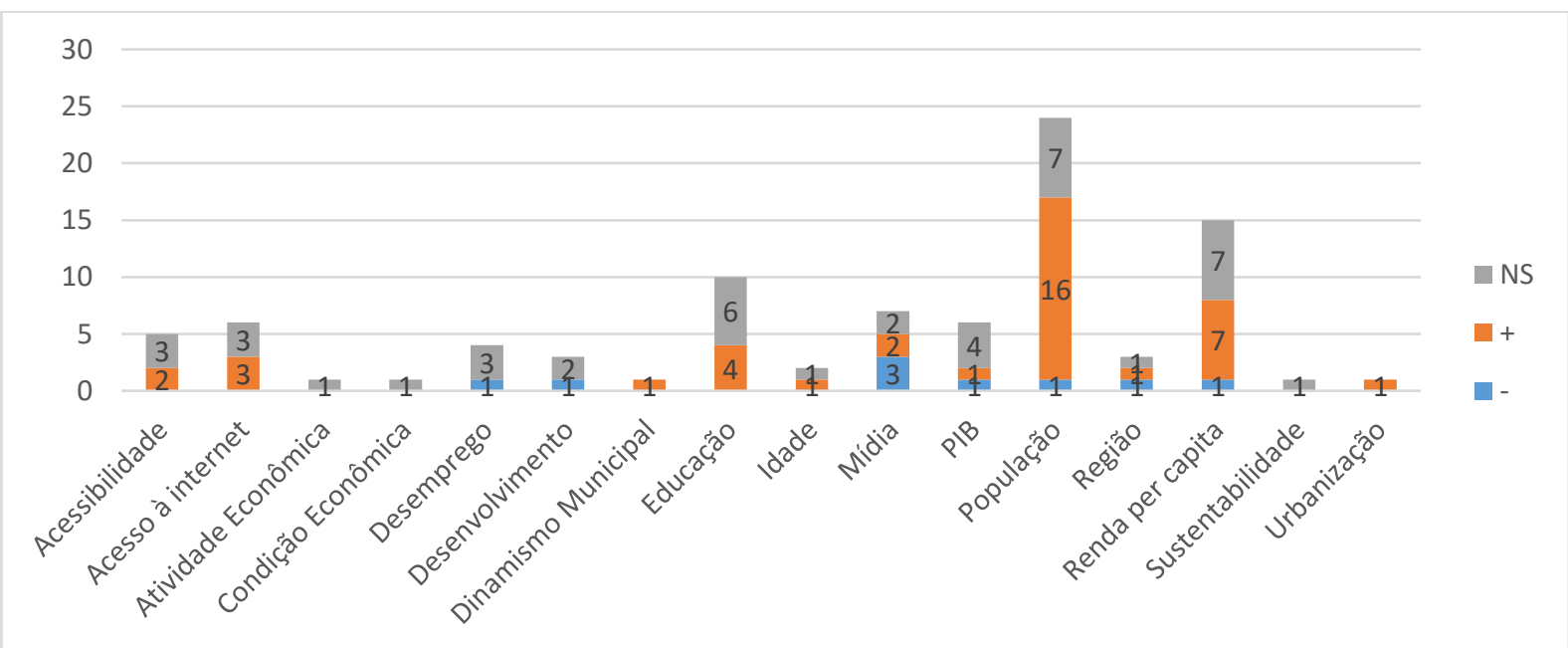

Figura 1 - Quantidade de Estudos por determinante socioeconômico

Fonte: os autores (2019). 
Diferentes explicações e pressupostos teóricos foram utilizados para justificar a associação dessas variáveis com a transparência. A partir da leitura e conclusões desses trabalhos observou-se que a associação positiva entre população, renda per capita e educação é consolidada. Em síntese, a Tabela 3 apresenta essas explicações o e respectivo pressuposto teórico.

Tabela 3 - Explicação e Pressuposto Teórico dos Determinantes Socioeconômicos

\begin{tabular}{cccc}
\hline Variáveis & Relação & \multicolumn{1}{c}{ Explicação } & $\begin{array}{c}\text { Pressuposto } \\
\text { Teórico }\end{array}$ \\
\hline População & & $\begin{array}{l}\text { A transparência é uma ferramenta que diminui os custos de } \\
\text { agência e a assimetria de informação, uma vez que são mais } \\
\text { evidentes em municípios maiores. }\end{array}$ & $\begin{array}{c}\text { Conflito de agência } \\
\text { e assimetria de } \\
\text { informação }\end{array}$ \\
\hline $\begin{array}{c}\text { Renda } \\
\text { Municipal }\end{array}$ & & $\begin{array}{l}\text { A riqueza municipal deve ser associada positivamente ao } \\
\text { aumento da transparência porque fornece um sinal de } \\
\text { qualidade de gestão, que pode beneficiar os políticos locais } \\
\text { aumentando suas chances de reeleição e reduzindo os custos } \\
\text { de agência. }\end{array}$ & $\begin{array}{c}\text { Conflito de agência } \\
\text { e Public Choice }\end{array}$ \\
\hline Educação & + & $\begin{array}{l}\text { Uma população com nível de educação elevada exercerá } \\
\text { pressão sobre as administrações públicas para divulgar } \\
\text { informações, o que eleva o nível de transparência. }\end{array}$ & Conflito de agência \\
\hline
\end{tabular}

Fonte: Os Autores (2019)

A transparência pública permite aumentar a interação entre cidadãos e governos, distinguindo, portanto, da administração pública tradicional. A participação desses cidadãos pode influência os níveis de transparência estabelecidos pelos governos, o que justifica as diferentes características socioeconômicas representarem-se como determinantes para a transparência pública.

O outro grupo de variáveis destacado nos estudos anteriores representam as características financeira-orçamentárias. A Tabela 4 apresenta esses determinantes e a relação (positiva, negativa ou não significante) encontrada em cada um dos estudos analisados (ALCAIDE MUÑOZ; RODRÍGUEZ BOLÍVAR; LÓPEZ HERNÁNDEZ, 2016; ALT; LASSEN, 2006; BAIRRAL; SILVA; ALVES, 2015; CAAMAÑO-ALEGRE; LAGO-PEÑAS; REYES-SANTIAS; SANTIAGO-BOUBETA, 2013; CABA PÉREZ; PEDRO RODRÍGUEZ BOLÍVAR; LÓPEZ HERNÁNDEZ, 2008; CÁRCABA GARCÍA; GARCÍA GARCÍA, 2010; CHENG, 1992; CRUZ; SILVA; SANTOS, 2010; ESTELLER-MORÉ; OTERO， 2012; FIIRST; COSTA; BALDISSERA; DALL'ASTA, 2017; GANDÍA; ARCHIDONA, 2008; GIROUX, 1989; GUILLAMÓN; BASTIDA; BENITO, 2011; GUILLAMÓN; RÍOS; GESUELE; METALLO, 2016; INGRAM, 1984; KEERASUNTONPONG; DUNSTAN; KHANNA, 2015; LASWAD; FISHER; OYELERE, 2005; MARTANI; LESTIANI, 2012; PURON-CID; BOLÍVAR, 2018; RODRÍGUEZ BOLÍVAR; ALCAIDE MUÑOZ; LÓPEZ HERNÁNDEZ, 2013; SANTANA JUNIOR, 2008; SMITH, 2004; SOL, 2013).

Tabela 4 - Determinantes Financeiro-Orçamentários nos Estudos Anteriores

\begin{tabular}{ccc}
\hline Variáveis & \multicolumn{2}{c}{ Relação } \\
\hline & \multicolumn{2}{c}{ DETERMINANTES FINANCEIRO-ORÇAMENTÁRIOS } \\
\hline \multirow{3}{*}{ Condição Financeira } & + & $\begin{array}{l}\text { Rodríguez Bolívar et al. (2013); Alcaraz-Quiles et al. (2015); Alcaide } \\
\text { Muñoz et al. (2016) }\end{array}$ \\
\cline { 2 - 3 } & & Fiirst et al. (2017) \\
\cline { 2 - 3 } Saldo Público & NS & Giroux (1989); Serrano-Cinca et al. (2009); Guillamón et al. (2016); \\
\cline { 2 - 3 } & + & Caamaño-Alegre et al. (2013); Rios et al. (2013); \\
\hline Dívida & + & Sol (2013); Alcaraz-Quiles et al. (2015); \\
\hline
\end{tabular}




\begin{tabular}{|c|c|c|}
\hline & - & $\begin{array}{l}\text { Cheng (1992); Smith (2004); Alt e Lassen (2006); Caba Pérez et al. } \\
\text { (2014); }\end{array}$ \\
\hline & NS & $\begin{array}{l}\text { Serrano-Cinca et al. (2009); Guillamón et al. (2011); Caamaño-Alegre et } \\
\text { al. (2013); Sol (2013); Alcaraz-Quiles et al. (2015); Fiirst et al. (2017) }\end{array}$ \\
\hline \multirow{3}{*}{ Receitas } & + & $\begin{array}{l}\text { Santana Junior (2008); Cruz (2010); Guillamón et al. (2011); } \\
\text { Keerasuntonpon et al. (2015); }\end{array}$ \\
\hline & - & Fiirst et al. (2017) \\
\hline & NS & Laswad et al. (2005); Caba Pérez et al. (2008); Bairral et al. (2015); \\
\hline \multirow{3}{*}{$\begin{array}{l}\text { Transferências } \\
\text { Intergovernamentais }\end{array}$} & + & $\begin{array}{l}\text { Guillamón et al. (2011); Rodríguez Bolívar et al. (2013); Alcaide Muñoz } \\
\text { et al. (2016) }\end{array}$ \\
\hline & - & Cheng (1992); Fiirst et al. (2017) \\
\hline & NS & $\begin{array}{l}\text { Caba Pérez et al. (2008); Esteller-Moré e Otero (2012); Martani e } \\
\text { Lestiani (2012); Bairral et al. (2015); }\end{array}$ \\
\hline $\begin{array}{l}\text { Viabilidade } \\
\text { Financeira }\end{array}$ & NS & Fiirst et al. (2017) \\
\hline Alavancagem & - & Guillamón et al. (2016); \\
\hline Financeira & NS & Laswad et al. (2005); Gandia e Archidona (2008); \\
\hline Regimes Contábil & NS & Giroux (1989); \\
\hline Ativos & + & Santana Junior (2008); Keerasuntonpon et al. (2015); \\
\hline Passivo & + & Santana Junior (2008); \\
\hline \multirow{3}{*}{ Despesa } & + & Santana Junior (2008); Gallego-Álvarez, et al. (2010); \\
\hline & - & Caamaño-Alegre et al. (2013); \\
\hline & NS & García-Sánchez et al. (2013); \\
\hline $\begin{array}{l}\text { Receita Corrente } \\
\text { Líquida }\end{array}$ & + & Santana Junior (2008); \\
\hline \multirow{2}{*}{$\begin{array}{l}\text { Investimento de } \\
\text { Capital }\end{array}$} & + & Cárcaba-García e García-García (2010); \\
\hline & NS & Fiirst et al. (2017) \\
\hline Déficit & NS & Guillamón et al. (2011); Esteller-Moré e Otero (2012); \\
\hline \multirow{2}{*}{ Gasto com Pessoal } & + & Bairral et al. (2015); \\
\hline & NS & Fiirst et al. (2017) \\
\hline
\end{tabular}

Fonte: Os Autores (2019)

As condições financeiras-orçamentárias representam os fatores internos e externos ligados ao ente público. Está relacionado à necessidade dos governos em realizar estruturas e práticas com o objetivo de demonstrar que estão cumprindo seu dever de transparência e responsabilidade sobre o uso dos recursos financeiros e orçamentários públicos (Alcaide Muñoz et al., 2016). Assim, justifica o uso de variáveis que buscam captar a condição financeira, a dívida, as transferências intergovernamentais e os investimentos de capital dos municípios para verificar o impacto na transparência pública.

A Figura 2 representa a quantidade de estudos que obtiveram algum tipo de relação para cada uma das variáveis relacionadas a aspectos socioeconômicos. 


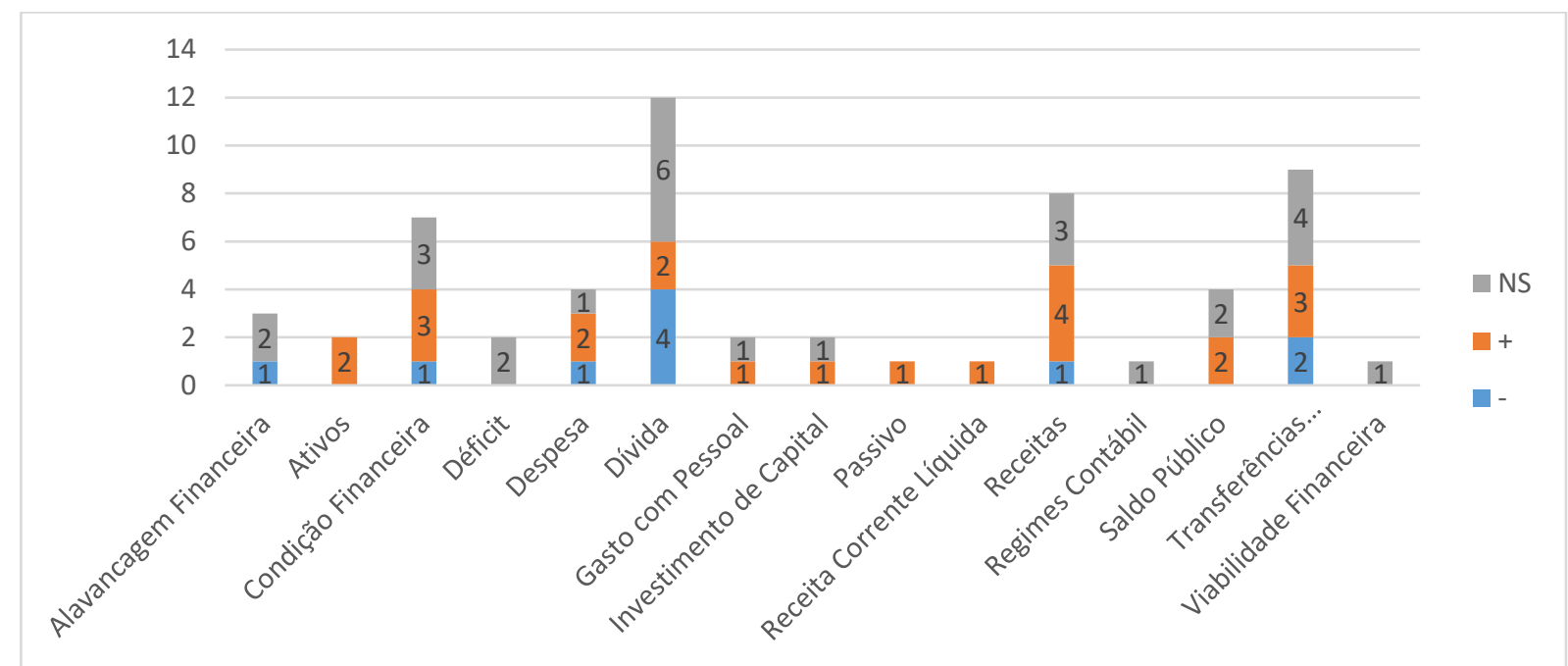

Figura 2 - Quantidade de Estudos por determinante financeiro-orçamentário Fonte: Os Autores (2019)

Observa-se que a dívida, as transferências intergovernamentais, as receitas e a condição financeira foram variáveis de grande interesse nesses estudos. Ainda assim, diferentes resultados foram obtidos para cada um desses estudos, o que mostra que a relação da transparência com essas variáveis é um fenômeno complexo e as características que identifica cada um dos estudos pode significar um resultado diferente. Essas diferenças podem ser justificadas devido à cultura administrativa, regime contábil e o próprio nível de governo (ALCAIDE MUÑOZ; RODRÍGUEZ BOLÍVAR; LÓPEZ HERNÁNDEZ, 2016).

A Tabela 5 sintetiza as explicações e pressupostos teóricos identificados na literatura para os principais determinantes financeiro-orçamentários.

Tabela 5 - Explicação e Pressuposto Teórico dos Determinantes Financeiro-Orçamentários

\begin{tabular}{|c|c|c|c|}
\hline Variáveis & Relação & Explicação & $\begin{array}{c}\text { Pressuposto } \\
\text { Teórico }\end{array}$ \\
\hline $\begin{array}{l}\text { Condição } \\
\text { Financeira }\end{array}$ & $+/-$ & $\begin{array}{l}\text { A condição financeira está associada à credibilidade } \\
\text { financeira das agências governamentais, assim como à } \\
\text { capacidade do governo de atender a seus compromissos } \\
\text { de pagamento e, por isso, os gestores públicos buscam } \\
\text { se legitimar ao se mostrarem mais transparentes quando } \\
\text { estão em uma situação de desempenho elevado. }\end{array}$ & $\begin{array}{c}\text { Comportamento } \\
\text { Oportunista e } \\
\text { Legitimidade }\end{array}$ \\
\hline Dívida & - & $\begin{array}{l}\text { Os gestores públicos divulgam mais informações quando } \\
\text { estão com um endividamento baixo, uma vez que isso } \\
\text { demonstra a responsabilidade e a eficácia dos entes } \\
\text { municipais na execução da gestão pública. }\end{array}$ & $\begin{array}{c}\text { Comportamento } \\
\text { Oportunista e } \\
\text { Legitimidade }\end{array}$ \\
\hline $\begin{array}{l}\text { Transferências } \\
\text { Intergov. }\end{array}$ & + & $\begin{array}{l}\text { A não vinculação e a obrigatoriedade de aplicação dos } \\
\text { recursos recebidos por meio de transferências } \\
\text { intergovernamentais desestimulam a arrecadação } \\
\text { tributária local, reduzem a accountability e a } \\
\text { responsabilidade fiscal }\end{array}$ & $\begin{array}{c}\text { Teoria da llusão } \\
\text { Fiscal e Flypaper } \\
\text { effect }\end{array}$ \\
\hline
\end{tabular}

Fonte: Os Autores (2019)

As características financeiras e orçamentárias representam fatores internos e externos à entidade. A condição financeira é uma medida de credibilidade, por isso pode justificar o movimento no nível de transparência que o governo quer estabelecer de acordo com sua condição atual. A dívida representa uma medida de desempenho, também associando a aspectos da qualidade da gestão e com isso o governo poderia querer divulgar esse tipo de informação. 
Por fim, as transferências intergovernamentais representam o vínculo que os governos têm entre eles, e a transparência busca representar a prestação de contas desse governo.

O terceiro grupo de variáveis destacado na literatura anterior representa as características financeira-orçamentárias. A Tabela 6 apresenta esses determinantes e a relação (positiva, negativa ou não significante) encontrada em cada um deles (ALCAIDE MUÑOZ; RODRÍGUEZ BOLÍVAR; LÓPEZ HERNÁNDEZ, 2016; ALT; LASSEN, 2006; CABA PÉREZ; PEDRO RODRÍGUEZ BOLÍVAR; LÓPEZ HERNÁNDEZ, 2008; CABA PEREZ; RODRÍGUEZ BOLÍVAR; LÓPEZ HERNÁNDEZ, 2014; CÁRCABA GARCÍA; GARCÍA GARCÍA, 2010; GANDÍA; ARCHIDONA, 2008; GARCÍA-TABUYO; SÁEZ-MARTÍN; CABA-PÉREZ, 2016; GIROUX, 1989; GUILLAMÓN; BASTIDA; BENITO, 2011; GUILLAMÓN; RÍOS; GESUELE; METALLO, 2016; INGRAM, 1984; LASWAD; FISHER; OYELERE, 2005; PURON-CID; BOLÍVAR, 2018; RÍOS; BENITO; BASTIDA, 2013; SERRANO-CINCA; RUEDA-TOMÁS; PORTILLO-TARRAGONA, 2009; SMITH, 2004; SOL, 2013; WEHNER; DE RENZIO, 2013).

Tabela 6 - Determinantes Políticos nos Estudos Anteriores

\begin{tabular}{|c|c|c|}
\hline Variáveis & Relação & Autores \\
\hline & & DETERMINANTES POLÍTICOS \\
\hline \multirow{3}{*}{ Competição Política } & + & $\begin{array}{l}\text { Ingram (1984); Gandia e Archidona (2008); Cárcaba-García e García- } \\
\text { García (2010); Gallego-Álvarez, et al. (2010); Rodríguez Bolívar et al. } \\
\text { (2013); Caba Pérez et al. (2014); Alcaide Muñoz et al. (2016) }\end{array}$ \\
\hline & - & Cheng (1992); Esteller-Moré e Otero (2012); Rios et al. (2013); \\
\hline & NS & $\begin{array}{l}\text { Smith (2004); Laswad et al. (2005); Caba Pérez et al. (2008); Serrano- } \\
\text { Cinca et al. (2009); García-Sánchez et al. (2013); }\end{array}$ \\
\hline \multirow{2}{*}{ Participação Política } & + & Serrano-Cinca et al. (2009); \\
\hline & NS & Gandia e Archidona (2008); Caamaño-Alegre et al. (2013); \\
\hline Democracia & + & Wehner e Renzio (2013); \\
\hline \multirow{2}{*}{$\begin{array}{l}\text { Ideologia Política - } \\
\text { Direita }\end{array}$} & - & Guillamón et al. (2011); García-Sánchez et al. (2013); Rios et al. (2013); \\
\hline & NS & $\begin{array}{l}\text { Serrano-Cinca et al. (2009); Gallego-Álvarez, et al. (2010); Esteller- } \\
\text { Moré e Otero (2012); Guillamón et al. (2016); }\end{array}$ \\
\hline $\begin{array}{l}\text { Ideologia Política - } \\
\text { Esquerda }\end{array}$ & + & Caamaño-Alegre et al. (2013); Sol (2013); \\
\hline $\begin{array}{c}\text { Forção Política } \\
\text { (índice Herfindahl) }\end{array}$ & NS & Guillamón et al. (2011); García-Sánchez et al. (2013); \\
\hline Taxa de Participção & NS & $\begin{array}{l}\text { Serrano-Cinca et al. (2009); Guillamón et al. (2011); Rios et al. (2013); } \\
\text { Sol (2013); }\end{array}$ \\
\hline Poder de Nomeação & NS & Ingram (1984); Cheng (1992); \\
\hline $\begin{array}{l}\text { Seleção do } \\
\text { Administrador }\end{array}$ & + & Ingram (1984); \\
\hline Grupos de Interesse & - & Cheng (1992); \\
\hline \multirow[b]{2}{*}{ Maioria Política } & - & Sol (2013); \\
\hline & NS & $\begin{array}{l}\text { Gandia e Archidona (2008); Alcaraz-Quiles et al. (2015); Puron-Cid e } \\
\text { Bolívar (2017) }\end{array}$ \\
\hline \multirow[b]{2}{*}{ Coligação Partidária } & - & Caamaño-Alegre et al. (2013); \\
\hline & NS & $\begin{array}{l}\text { Serrano-Cinca et al. (2009); Gallego-Álvarez, et al. (2010); Puron-Cid e } \\
\text { Bolívar (2017) }\end{array}$ \\
\hline Gênero & NS & $\begin{array}{l}\text { Guillamón et al. (2011); Rios et al. (2013); Sol (2013); Guillamón et al. } \\
\text { (2016); }\end{array}$ \\
\hline
\end{tabular}

Fonte: Os Autores (2019)

$\mathrm{O}$ ambiente político também tem se mostrado presente e justificado as variações percebidas nos níveis de transparência. Entre as principais justificativas para o uso dessas variáveis para verificar o impacto na transparência, é a existência de ciclos políticos e o 
comportamento oportunista para se manter no poder ou ser reeleito. A divulgação das informações pode ser uma técnica utilizada para mitigar problemas entre partidos políticos de oposição, assim como a capacidade de influenciar na manutenção no poder ou na reeleição. Por essa razão é que o uso das variáveis competição política, ideologia política e coligação partidária tem se consagrado nos estudos. A Figura 3 ilustra a quantidade de estudos por determinante.

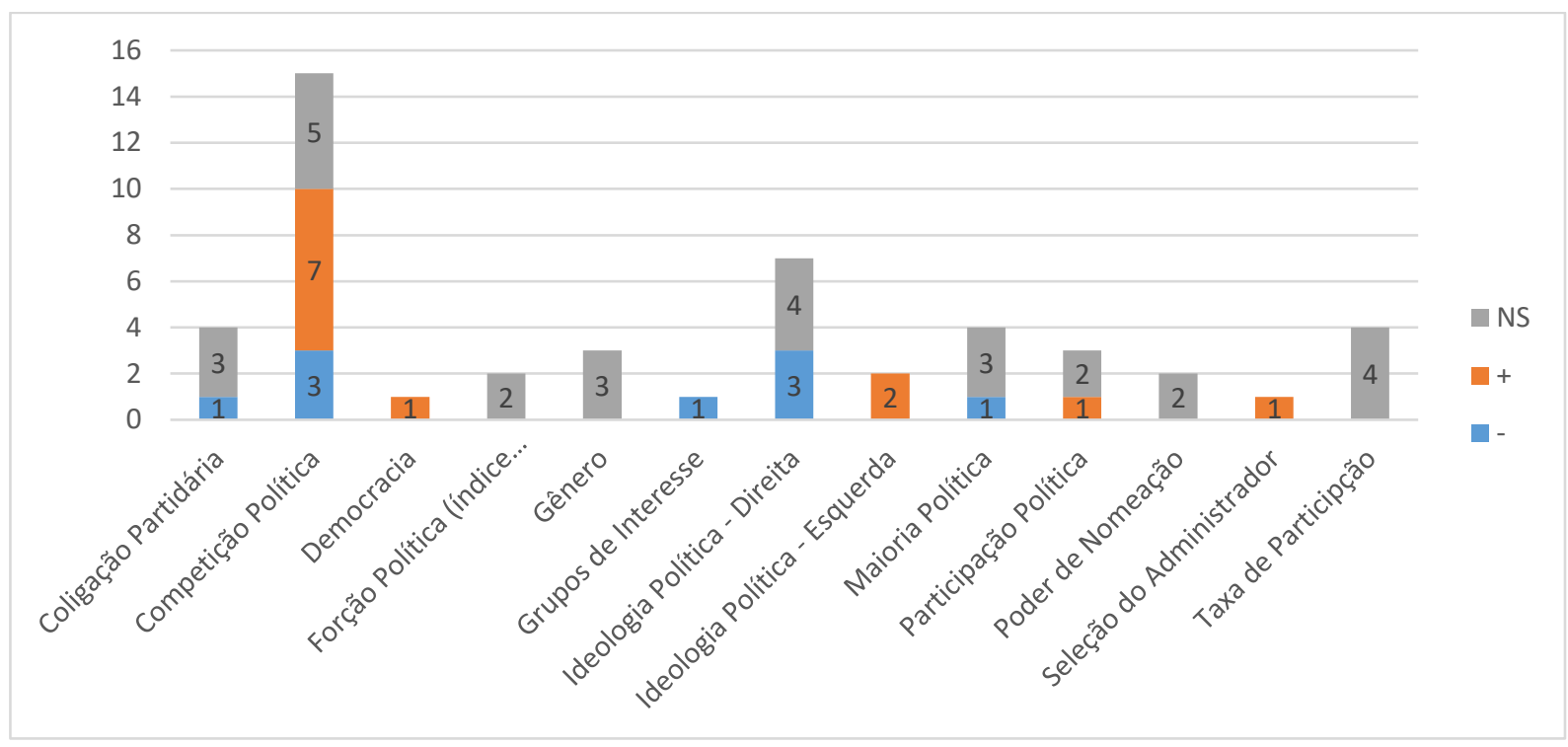

Figura 3 - Quantidade de Estudos por determinante político

Fonte: Os Autores (2019)

A competição política foi a variável mais utilizada nos estudos anteriores. Ainda que se observem estudos que não tenham comprovado a relação significativa (CABA PÉREZ; PEDRO RODRÍGUEZ BOLÍVAR; LÓPEZ HERNÁNDEZ, 2008; GARCÍA-SÁNCHEZ; FRÍASACEITUNO; RODRÍGUEZ-DOMÍNGUEZ, 2013; LASWAD; FISHER; OYELERE, 2005; SERRANO-CINCA; RUEDA-TOMÁS; PORTILLO-TARRAGONA, 2009; SMITH, 2004), ou até mesmo contrária à transparência (CHENG, 1992; ESTELLER-MORÉ; OTERO, 2012; RÍOS; BENITO; BASTIDA, 2013), a maior parte da literatura se direciona para a associação positiva (ALCAIDE MUÑOZ; RODRÍGUEZ BOLÍVAR; LÓPEZ HERNÁNDEZ, 2016; CABA PEREZ; RODRÍGUEZ BOLÍVAR; LÓPEZ HERNÁNDEZ, 2014; CÁRCABA GARCÍA; GARCÍA GARCÍA, 2010; GALLEGO-ÁLVAREZ; RODRÍGUEZ-DOMÍNGUEZ; GARCÍA-SÁNCHEZ, 2010; GANDÍA; ARCHIDONA, 2008; INGRAM, 1984; RODRÍGUEZ BOLÍVAR; ALCAIDE MUÑOZ; LÓPEZ HERNÁNDEZ, 2013). Essa diversidade de resultado justifica-se pelas diferenças institucionais e econômicas de cada governo (PURONCID; BOLÍVAR, 2018).

Outros estudos também abordaram a questão da influência da ideologia partidária, seja de direita, seja de esquerda, na transparência. Entretanto, a direção da influência depende da natureza da informação do governo local em jogo e do partido no poder nesse momento (PIOTROWSKI; VAN RYZIN, 2007). Evidências anteriores indicam que partidos mais à esquerda apresentam um nível de transparência maior (CAAMAÑO-ALEGRE; LAGOPEÑAS; REYES-SANTIAS; SANTIAGO-BOUBETA, 2013; SOL, 2013), e partidos mais à direita, consequentemente, tem um nível de transparência menor (GARCÍA-SÁNCHEZ; FRÍAS-ACEITUNO; RODRÍGUEZ-DOMÍNGUEZ， 2013; GUILLAMÓN; BASTIDA; BENITO, 2011; RÍOS; BENITO; BASTIDA, 2013).

A competição política, maioria política e taxa de participação, cada um com quatro estudos identificados, foram variáveis de interesse. Dessa forma, considerando as principais 
variáveis políticas, apresenta-se na Tabela 7 com a relação proeminente, explicação e pressuposto teórico.

Tabela 7 - Explicação e Pressuposto Teórico dos Determinantes Políticos

\begin{tabular}{|c|c|c|c|}
\hline Variáveis & Relação & Explicação & $\begin{array}{c}\text { Pressuposto } \\
\text { Teórico }\end{array}$ \\
\hline $\begin{array}{c}\text { Competição } \\
\text { Política }\end{array}$ & + & $\begin{array}{l}\text { A existência de rivais políticos que apresentem forte } \\
\text { oposição ao partido no poder aumenta os custos em } \\
\text { longo prazo do descumprimento das promessas pré- } \\
\text { eleitorais, o que obriga os gestores públicos a } \\
\text { justificarem suas ações e, com isso, a se mostrarem } \\
\text { mais transparentes. }\end{array}$ & $\begin{array}{l}\text { Conflito de } \\
\text { Agência e } \\
\text { Assimetria da } \\
\text { Informação }\end{array}$ \\
\hline $\begin{array}{l}\text { Ideologia } \\
\text { Política }\end{array}$ & $+1-$ & $\begin{array}{l}\text { Os partidos de direita visam a reduções orçamentárias } \\
\text { e a uma gestão mais responsável, por isso buscam se } \\
\text { mostrarem mais transparentes, já que tendem } \\
\text { mostrar seu desempenho para toda a sociedade. }\end{array}$ & $\begin{array}{l}\text { Comportamento } \\
\text { Ideológico e } \\
\text { Legitimidade }\end{array}$ \\
\hline
\end{tabular}

Fonte: Os Autores (2019)

Tem-se como premissa que os políticos têm o desejo de ganhar ou se manter no poder, por isso suas escolhas públicas normalmente são direcionadas nesse sentido. Considerando que a função social é um subproduto das escolhas privadas dos gestores públicos, espera-se que as variáveis competição política e ideologia política possam explicam a variação nos níveis de transparência.

Um último grupo de determinantes foi identificado nos estudos anteriores, trata-se de variáveis governamentais. A Tabela 8 apresenta esses determinantes e a relação (positiva, negativa ou não significante) encontrada em cada um.

Tabela 8 - Determinantes Governamentais nos Estudos Anteriores

\begin{tabular}{|c|c|c|}
\hline Variáveis & Relação & $\begin{array}{ll}\text { Autores } \\
\end{array}$ \\
\hline \multicolumn{3}{|c|}{ DETERMINANTES GOVERNAMENTAIS } \\
\hline \multirow{3}{*}{ Preço dos Impostos } & + & Puron-Cid e Bolívar (2017) \\
\hline & - & Giroux (1989); Alcaraz-Quiles et al. (2015); \\
\hline & NS & Caamaño-Alegre et al. (2013); \\
\hline \multirow{3}{*}{ Burocracia } & + & Cheng (1992); \\
\hline & - & Bairral et al. (2015); \\
\hline & NS & Giroux (1989); \\
\hline \multirow{2}{*}{ Tipo de Governo } & + & Giroux (1989); Bairral et al. (2015); \\
\hline & NS & Guillamón et al. (2016); Puron-Cid e Bolívar (2017) \\
\hline \multirow{3}{*}{$\begin{array}{l}\text { Qualidade da } \\
\text { Auditoria }\end{array}$} & + & Pina et al. (2010); Martani e Lestiani (2012); \\
\hline & - & Giroux (1989); \\
\hline & NS & Smith (2004); \\
\hline Estilo de & & Pina et al. (2010); Rios et al. (2013); \\
\hline $\begin{array}{c}\text { Administração } \\
\text { Pública }\end{array}$ & + & \\
\hline Governança & - & Cheng (1992); \\
\hline Forma de Governo & NS & Smith (2004); Caba Pérez et al. (2014); \\
\hline Tipo de Conselho & NS & Laswad et al. (2005); \\
\hline Corrupção & NS & Pina et al. (2010); \\
\hline \multirow{2}{*}{ LAI } & + & Puron-Cid e Bolívar (2017) \\
\hline & - & Garcia-Tabuyo et al. (2015) \\
\hline
\end{tabular}

Fonte: Os Autores (2019) 
Os determinantes governamentais estão associados a questões de desempenho, retratando a forma como as entidades públicas formulam, planejam, implementam suas políticas públicas e controlam suas funções estatais visando o bem-estar social (BAIRRAL; SILVA; ALVES, 2015). A Figura 4 apresenta a quantidade de estudos que obtiveram algum tipo de relação para cada uma das variáveis relacionadas a aspectos governamentais.

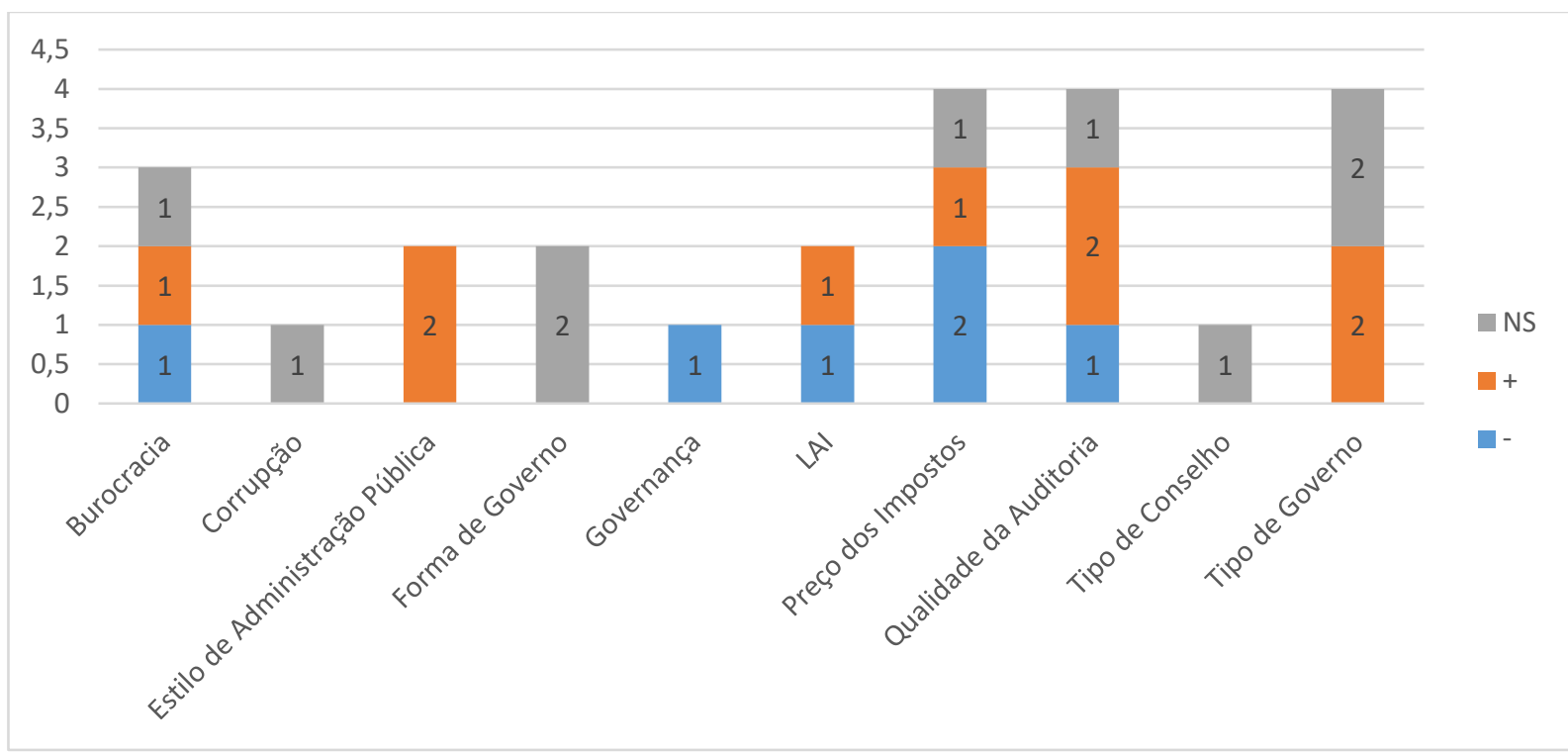

Figura 4 - Quantidade de Estudos por determinante governamental Fonte: Os Autores (2019)

Há menos variáveis governamentais nos estudos que abordam os determinantes da transparência pública. Ainda assim, quatro estudos utilizaram o preço dos impostos, qualidade da auditoria e tipo de governo como determinante. A burocracia também foi utilizada em três estudos anteriores. Os resultados parecem não chegar a um consenso se existe uma relação positiva ou negativa. Esses resultados se justificam uma vez que existem uma diversidade de entidades governamentais analisadas, de objetivos e a dificuldade de coleta e mensuração de dados (BAIRRAL; SILVA; ALVES, 2015).

A Tabela 9 sintetiza a explicação e o pressuposto teórico para as principais variáveis.

Tabela 9 - Explicação e Pressuposto Teórico dos Determinantes Governamentais

\begin{tabular}{|c|c|c|c|}
\hline Variáveis & Relação & Explicação & $\begin{array}{c}\text { Pressuposto } \\
\text { Teórico }\end{array}$ \\
\hline $\begin{array}{l}\text { Preço dos } \\
\text { impostos }\end{array}$ & $+/-$ & $\begin{array}{l}\text { O gestor público não irá dar transparência quando } \\
\text { está aumentando o preço dos impostos, assim como } \\
\text { irá buscar esse objetivo quando o reduz. }\end{array}$ & $\begin{array}{l}\text { Assimetria da } \\
\text { Informação }\end{array}$ \\
\hline $\begin{array}{c}\text { Qualidade da } \\
\text { Auditoria }\end{array}$ & $+/-$ & $\begin{array}{l}\text { A auditoria representa termos de compliance, por isso } \\
\text { espera-se que quanto mais atuante for sobre ações do } \\
\text { gestor público, mais esse buscará por transparência } \\
\text { para atender aos diferentes tipos de solicitações. }\end{array}$ & $\begin{array}{l}\text { Assimetria da } \\
\text { Informação e } \\
\text { Public Choice }\end{array}$ \\
\hline $\begin{array}{l}\text { Tipo de } \\
\text { Governo }\end{array}$ & + & $\begin{array}{l}\text { A forma de administração pública mais gerencial busca } \\
\text { a adotar melhores práticas de divulgação, pois os } \\
\text { gestores são mais bem preparados em quesitos de } \\
\text { administração que incluem as práticas de desempenho, } \\
\text { como a adoção da controladoria e indicadores de } \\
\text { desempenho, o que reduz a assimetria informacional. }\end{array}$ & $\begin{array}{l}\text { Assimetria da } \\
\text { Informação }\end{array}$ \\
\hline
\end{tabular}




\begin{tabular}{lll}
\hline & A burocracia pública prefere baixos níveis de & \\
evidenciação para manter o poder e, Assimetria da & consequentemente, uma monitoração ineficiente, & Informação e \\
Burocracia & $+/-$ & $\begin{array}{l}\text { tendendo a um efeito negativo nas práticas de } \\
\text { evidenciação. }\end{array}$ \\
\hline
\end{tabular}

Fonte: Os Autores (2019)

As características governamentais representam aspectos estruturais do governo, cada uma das diferentes variáveis representam um aspecto que envolve sua influência na transparência. $\mathrm{O}$ gestor público tende a não se mostrar mais transparente quando aumento o preço dos impostos. Já a auditoria representa termos de compliance, de modo que gestor irá se mostrar transparente para atender aos diferentes tipos de solicitações. O tipo de governo capta as diferentes características de cada um, em que a administração pública mais gerencial tende a se mostrar mais transparente que as demais. Por fim, a burocracia pública prefere baixos níveis de evidenciação, assim se mostrando menos transparente.

Portanto, reafirma-se a transparência como um fenômeno complexo e que merece ser estudo. A literatura anterior não chega a uma conclusão final e de tempos em tempos vai incluindo outras variáveis que parecem explicar a variação da transparência do governo. Tendo feito essas considerações, a próxima seção apresenta as conclusões desse estudo.

\section{CONCLUSÃO}

Essa pesquisa partiu do objetivo de analisar os determinantes da transparência pública observados na literatura teórica e empírica. Para tanto, desenvolveu-se uma pesquisa descritiva, documental e essencialmente qualitativa. Realizou-se uma busca e análise de artigos indexados nas bases científicas SPELL, SCOPUS e Web of Science, resultando ao final 33 artigos, os quais, com o auxílio da análise bibliométrica e de conteúdo, permitiram compreender o panorama das pesquisas relacionadas aos determinantes da transparência pública.

A transparência é um desafio para a reforma da administração pública e para uma governança moderna e melhor. A transparência é considerada como um valor democrático por excelência que sustenta a confiabilidade do governo em um desempenho alto e responsável. A compreensão do conceito, determinantes e consequências se mostram úteis nos estudos que envolvem este tema.

Os estudos têm observado que entre os principais determinantes da transparência pública estão os aspectos socioeconômicos, financeiro-orçamentários, políticos e governamentais. As primeiras pesquisas sobre o tema tiveram início em 1984, a partir dos relatórios anuais publicados em nível estadual dos EUA (INGRAM, 1984), e tem continuados até o momento atual (PURON-CID; BOLÍVAR, 2018).

Aspectos socioeconômicos parecem influenciar positivamente a transparência pública, observado pelas variáveis que representam a população, renda municipal e educação. Essa associação é justificada pelo fato de que municípios maiores exigem mais informações, por isso a transparência trata-se de um mecanismo de diminuir os custos de agência e assimetria de informação. $\mathrm{O}$ aumento da riqueza municipal simboliza a qualidade da gestão, por isso os gestores buscam demonstrar isso. Pessoas mais bem-educadas exercem mais pressão sobre o governo, em resposta a isso o governo se mostra mais transparente.

Os aspectos financeiros-orçamentários representam o desempenho em termos financeiros e orçamentários, representando tanto aspectos inerentes a gestão, assim como representam como estão as contas públicas do governo, sua condição financeira, seu nível de dívida, arrecadação de receitas e dependência de recursos de outros entes. A condição financeira condiz com a credibilidade financeira, e vai dizer se o governo conseguirá ou não cumprir com suas obrigações de pagamento, isto é, condição financeira melhor, mais transparência, senão o inverso. 
O ambiento político e eleitoral busca captar possíveis interesses particulares dos gestores sobre a transparência, dado a existência de ciclos políticos e o comportamento oportunista para se manter no poder ou ser reeleito, por isso as variáveis competição política, ideologia política e coligação partidária tem se consagrado nos estudos. Uma oposição forte obriga os gestores no poder a justificarem suas ações e, assim, se mostrarem mais transparentes. Questões ideológicas buscam captar o efeito das características de cada partido, uma vez que se espera que os partidos de esquerda favorecem o aumento da despesa pública, enquanto os partidos de direita visam a reduções orçamentárias (RÍOS; BENITO; BASTIDA, 2013).

Por último, os aspectos governamentais representando como os governos formulam, planejam, implementam suas políticas públicas e controlam suas funções estatais visando o bem-estar social (BAIRRAL; SILVA; ALVES, 2015). Os determinantes desse grupo são variáveis que representam o preço dos impostos, a qualidade de auditoria, o tipo de governo e a burocracia. As conclusões para essas variáveis ainda não foram consolidadas na literatura. As explicações para alguns resultados encontrados estão relacionadas ao fato de que os gestores dão mais transparência quando abaixam o preço dos impostos, assim como quanto mais houver e melhor for a qualidade da auditoria, mais esses gestores buscarão por transparência. A novo tipo de administração, a gerencial, também busca mais por transparência, diferente dos demais, assim como aspectos burocráticos têm a característica de serem menos transparentes.

Apesar de já existirem vários estudos sobre os determinantes da transparência, o assunto ainda merece ser explorado, uma vez que se faz necessário melhor entendimento a respeito dos aspectos políticos, eleitorais e governamentais, até então não existem explicações consolidadas, já que se trata de um fenômeno complexo (BUCHANAN, 1984; MEIJER, 2013). Outros estudos têm surgido e parecem se encaminhar para casos específicos, como um estudo realizado nos governos locais chineses (SUN; ANDREWS, 2019), ou outros estudos que compararam diferentes países (CABA PEREZ; RODRÍGUEZ BOLÍVAR; LÓPEZ HERNÁNDEZ, 2014; GARCÍA-TABUYO; SÁEZ-MARTÍN; CABA-PÉREZ, 2016). Além disso, outras abordagens têm se destacado para entender a realidade que representa a transparência, utilizando modelos de equações estruturais com variáveis moderadoras (PURON-CID; BOLÍVAR, 2018).

As limitações dessa pesquisa estão relacionadas a forma de coleta e análise de dados, uma vez que outras pesquisas poderiam ter sido obtidas caso abordassem outras bases de dados ou até mesmo se tivesse utilizado outros tipos de filtros, mas, ainda assim, espera-se ter alcançado a maior parte da literatura. A análise também se restringiu por não ter sido feito a leitura de todos os trabalhos, somente nos pontos de interesse para essa pesquisa.

Futuras pesquisas devem ser direcionadas para preencher as lacunas nesse tema, observando especificidades de cada país, cultura, tipo de administração, contexto e considerar que a transparência é um fenômeno complexo o que exige metodologias robustas para entender o fenômeno, como é o caso de entender o efeito das variáveis moderados e mediadores sobre a transparência, assim como o próprio efeito da transparência nessas variáveis.

\section{REFERÊNCIAS}

ALCAIDE MUÑOZ, L.; RODRÍGUEZ BOLÍVAR, M. P.; LÓPEZ HERNÁNDEZ, A. M. Transparency in governments: a meta-analytic review of incentives for digital versus hard-copy public financial disclosures. The American Review of Public Administration, 47, n. 5, p. 550-573, 2016.

ALCARAZ-QUILES, F. J.; NAVARRO-GALERA, A.; ORTIZ-RODRIGUEZ, D. Factors determining online sustainability reporting by local governments. International Review of Administrative Sciences, 81, n. 1, p. 79-109, 2015.

ALT, J. E.; LASSEN, D. D. Fiscal transparency, political parties, and debt in OECD countries. European Economic Review, 50, n. 6, p. 1403-1439, 2006. 
BAIRRAL, M. A. d. C.; SILVA, A. H. C. e.; ALVES, F. J. d. S. Transparência no setor público: uma análise dos relatórios de gestão anuais de entidades públicas federais no ano de 2010 . Revista de Administração Pública-RAP, 49, n. 3, p. 643-675, 2015.

BESLEY, T.; SMART, M. Fiscal restraints and voter welfare. Journal of public Economics, 91, n. 3-4, p. 755-773, 2007.

BUCHANAN, J. M. Politics without romance: A sketch of positive public choice theory and its normative implications. The theory of public choice II, 11, p. 22, 1984.

BUCHANAN, J. M.; TULLOCK, G. The calculus of consent: Logical foundations of constitutional democracy (ann arbor paperbacks). 1962.

CAAMAÑO-ALEGRE, J.; LAGO-PEÑAS, S.; REYES-SANTIAS, F.; SANTIAGOBOUBETA, A. Budget transparency in local governments: an empirical analysis. Local Government Studies, 39, n. 2, p. 182-207, 2013.

CABA PÉREZ, C.; PEDRO RODRÍGUEZ BOLÍVAR, M.; LÓPEZ HERNÁNDEZ, A. M. eGovernment process and incentives for online public financial information. Online Information Review, 32, n. 3, p. 379-400, 2008.

CABA PEREZ, M. d. C.; RODRÍGUEZ BOLÍVAR, M. P.; LÓPEZ HERNÁNDEZ, A. M. The Determinants Of Government Financial Reports Online. Transylvanian Review of Administrative Sciences, 10, n. 42, p. 5-31, 2014.

CALDERÓN, C.; CHONG, A. Do Democracies Breed Rent-seeking Behavior? The Journal of Policy Reform, 9, n. 4, p. 247-260, 2006.

CÁRCABA GARCÍA, A. I.; GARCÍA GARCÍA, J. Determinants of online reporting of accounting information by Spanish local government authorities. Local Government Studies, 36, n. 5, p. 679-695, 2010.

CHENG, R. H. An empirical analysis of theories on factors influencing state government accounting disclosure. Journal of Accounting and Public Policy, 11, n. 1, p. 1-42, 1992.

CHIZZOTTI, A. Pesquisa em ciências humanas e sociais. Cortez editora, 2018. 8524926473.

CROSS, H. L. The people's right to know; legal access to public records and proceedings. New York: Columbia University Press, 1953. xxiv, 405 p. p., v. xxiv, 405 p.).

CRUZ, C. F.; FERREIRA, A. C. d. S.; SILVA, L. M. d.; MACEDO, M. Á. d. S. Transparência da gestão pública municipal: um estudo a partir dos portais eletrônicos dos maiores municípios brasileiros. 2012, 46, n. 1, p. 24, 2012-12-18 2012. transparência; gestão pública; portais eletrônicos; municípios.

CRUZ, C. F.; SILVA, L. M.; SANTOS, R. Transparência da gestão fiscal: um estudo a partir dos portais eletrônicos dos maiores municípios do Estado do Rio de Janeiro. Contabilidade, Gestão e Governança, 12, n. 3, p. 102-115, 2010.

ESTELlER-MORÉ, A.; OTERO, J. P. Fiscal Transparency: (Why) does your local government respond? Public Management Review, 14, n. 8, p. 1153-1173, 2012.

FIANI, R. Teoria dos Custos de Transação. In: ELSEVIER (Ed.). Economia industrial: fundamentos teóricos e práticos no Brasil 2ed. Rio de Janeiro, 2013. p. 169 - 181.

FIIRST, C.; COSTA, J. S.; BALDISSERA, J. F.; DALL'ASTA, D. A influência de variáveis socioeconômicas e contábeis no índice de transparência eletrônica dos maiores municípios brasileiros, após a lei de acesso à informação. In: Anpcont, 2017, Belo Horizonte, MG. 11.

FONSECA, E. N. Bibliometria: teoria e prática. Editora Cultrix, 1986. 8531600340. 
GALL, M. D.; BORG, W. R.; GALL, J. P. Educational research: An introduction. Longman Publishing, 1996. 0801309808.

GALLEGO-ÁLVAREZ, I.; RODRÍGUEZ-DOMÍNGUEZ, L.; GARCÍA-SÁNCHEZ, I.-M. Are determining factors of municipal E-government common to a worldwide municipal view? An intra-country comparison. Government Information Quarterly, 27, n. 4, p. 423-430, 2010 .

GANDÍA, J. L.; ARCHIDONA, M. C. Determinants of web site information by Spanish city councils. Online Information Review, 32, n. 1, p. 35-57, 2008.

GARCÍA-SÁNCHEZ, I.-M.; FRÍAS-ACEITUNO, J.-V.; RODRÍGUEZ-DOMÍNGUEZ, L. Determinants of corporate social disclosure in Spanish local governments. Journal of Cleaner Production, 39, p. 60-72, 2013.

GARCÍA-TABUYO, M.; SÁEZ-MARTÍN, A.; CABA-PÉREZ, M. D. C. Mandatory versus voluntary disclosures: Drivers of proactive information provision by local governments in Central America. Information Development, 32, n. 4, p. 1199-1215, 2016.

GIROUX, G. Political interests and governmental accounting disclosure. Journal of Accounting and Public Policy, 8, n. 3, p. 199-217, 1989.

GRIMMELIKHUIJSEN, S. G.; WELCH, E. W. Developing and testing a theoretical framework for computer-mediated transparency of local governments. Public administration review, 72, n. 4, p. 562-571, 2012.

GUILLAMÓN, M.-D.; BASTIDA, F.; BENITO, B. The determinants of local government's financial transparency. Local Government Studies, 37, n. 4, p. 391-406, 2011.

GUILlAMÓN, M.-D.; RÍOS, A.-M.; GESUELE, B.; METALLO, C. Factors influencing social media use in local governments: The case of Italy and Spain. Government Information Quarterly, 33, n. 3, p. 460-471, 2016.

HERZOG, B. Does transparency mitigate the political budget cycle? Journal of Economic Studies, 44, n. 5, p. 666-689, 2017.

HÖLMSTROM, B. Moral hazard and observability. The Bell journal of economics, 10, n. 1, p. 74-91, 1979.

HOOD, C. Transparency in historical perspective. Oxford University Press, 2006. v. 135). 0197263836.

INGRAM, R. W. Economic Incentives and the Choice of State Government Accounting Practices. Journal of Accounting Research, 22, n. 1, p. 126-144, 1984.

ISLAM, R. Does more transparency go along with better governance? Economics \& Politics, 18, n. 2, p. 121-167, 2006.

JENSEN, M. C.; MECKLING, W. H. Theory of the firm: Managerial behavior, agency costs and ownership structure. Journal of financial economics, 3, n. 4, p. 305-360, 1976.

KEERASUNTONPONG, P.; DUNSTAN, K.; KHANNA, B. Factors influencing disclosures of statements of service performance of New Zealand local authorities. Pacific Accounting Review, 27, n. 3, p. 304-328, 2015.

KRAAY, A.; KAUFMANN, D. Growth without governance. The World Bank, 2002.

LANE, J.-E. Public administration \& public management: The principal-agent perspective. Routledge, 2006. 1134199961. 
LASWAD, F.; FISHER, R.; OYELERE, P. Determinants of voluntary Internet financial reporting by local government authorities. Journal of Accounting and Public Policy, 24, n. 2, p. 101-121, 2005.

LOWATCHARIN, G.; MENIFIELD, C. E. Determinants of Internet-enabled transparency at the local level: A study of Midwestern county web sites. State and Local Government Review, 47, n. 2, p. 102-115, 2015.

MARTANI, D.; LESTIANI, A. Disclosure in local government financial statements: the case of Indonesia. Global Review of Accounting and Finance, 3, n. 1, p. 67-84, 2012.

MEIJER, A. Understanding modern transparency. International Review of Administrative Sciences, 75, n. 2, p. 255-269, 2009.

MEIJER, A. Understanding the complex dynamics of transparency. Public Administration Review, 73, n. 3, p. 429-439, 2013.

MILESI-FERRETTI, G. M. Good, bad or ugly? On the effects of fiscal rules with creative accounting. Journal of Public Economics, 88, n. 1-2, p. 377-394, 2004.

MUELLER, D. C. Public choice: A survey. Journal of Economic Literature, 14, n. 2, p. 395433, 1976.

OLIVEIRA, C. B. d.; FONTES FILHO, J. R. Problemas de agência no setor público: o papel dos intermediadores da relação entre poder central e unidades executoras. Revista de Administração Pública-RAP, 51, n. 4, p. 596-615, 2017.

OLIVER, R. What is transparency? McGraw Hill Professional, 2004. 0071435484.

PINA, V.; TORRES, L.; ROYO, S. Is e-government promoting convergence towards more accountable local governments? International Public Management Journal, 13, n. 4, p. 350$380,2010$.

PIOTROWSKI, S. J.; VAN RYZIN, G. G. Citizen attitudes toward transparency in local government. The American Review of Public Administration, 37, n. 3, p. 306-323, 2007.

POMEROY, B.; THORNTON, D. B. Meta-analysis and the accounting literature: The case of audit committee independence and financial reporting quality. European Accounting Review, 17, n. 2, p. 305-330, 2008.

PRAT, A., 2006, The more closely we are watched, the better we behave? OXFORD UNIVERSITY PRESS INC. 91.

PRATT, J. W.; ZECKHAUSER, R. J. Principals and Agents: The Structure of Business (Cambridge, Mass: Harvard Business School) p. 2. 1985.

PURON-CID, G.; BOLÍVAR, M. P. R. The effects of contextual factors into different features of financial transparency at the municipal level. Government Information Quarterly, 35, n. 1, p. 135-150, 2018.

RAUPP, F. M.; BEUREN, I. M. Metodologia da Pesquisa Aplicável às Ciências. Como elaborar trabalhos monográficos em contabilidade: teoria e prática. São Paulo: Atlas, 2006.

RÍOS, A.-M.; BENITO, B.; BASTIDA, F. Determinants of central government budget disclosure: an international comparative analysis. Journal of Comparative Policy Analysis: Research and Practice, 15, n. 3, p. 235-254, 2013. 
RODRÍGUEZ BOLÍVAR, M. P.; ALCAIDE MUÑOZ, L.; LÓPEZ HERNÁNDEZ, A. M. Determinants of financial transparency in government. International Public Management Journal, 16, n. 4, p. 557-602, 2013.

ROGOFF, K. Equilibrium Political Budget Cycles. The American Economic Review, 80, n. 1, p. 21-36, 1990.

ROGOFF, K.; SIBERT, A. Elections and macroeconomic policy cycles. The review of economic studies, 55, n. 1, p. 1-16, 1988.

SANTANA JUNIOR, J. J. B. d. Transparência fiscal eletrônica: uma análise dos níveis de transparência apresentados nos sites dos poderes e órgãos dos Estados e do Distrito Federal do Brasil. 2008. (Mestrado) -, Universidade Federal de Pernambuco, Recife, Brasil.

SATO, F. R. L. A teoria da agência no setor da saúde: o caso do relacionamento da Agência Nacional de Saúde Suplementar com as operadoras de planos de assistência supletiva no Brasil. Revista de Administração Pública, 41, n. 1, p. 49-62, 2007.

SERRANO-CINCA, C.; RUEDA-TOMÁS, M.; PORTILLO-TARRAGONA, P. Factors influencing e-disclosure in local public administrations. Environment and planning C: Government and Policy, 27, n. 2, p. 355-378, 2009.

SLOMSKI, V. Controladoria e governança na gestão pública. Editora Atlas SA, 2005. 8522466645.

SMITH, K. A. Voluntarily reporting performance measures to the public a test of accounting reports from US Cities. International Public Management Journal, 7, n. 1, p. 19, 2004.

SOL, D. A. d. The institutional, economic and social determinants of local government transparency. Journal of Economic Policy Reform, 16, n. 1, p. 90-107, 2013.

SUN, S.; ANDREWS, R. The determinants of fiscal transparency in Chinese city-level governments. Local Government Studies, p. 1-24, 2019.

VICENTE, E. F. R.; DO NASCIMENTO, L. S. A efetividade dos ciclos políticos nos municípios brasileiros: um enfoque contábil. Revista de Contabilidade e Organizações, 6 , $\mathrm{n}$. 14, p. 106-126, 2012.

WEHNER, J.; DE RENZIO, P. Citizens, legislators, and executive disclosure: The political determinants of fiscal transparency. World Development, 41, p. 96-108, 2013.

ZUCCOLOTTO, R.; RICCIO, E. L.; SAKATA, M. C. G. Characteristics of scientific production on governmental transparency. International Journal of Auditing Technology, 2, n. 2, p. 134-152, 2014. 